\author{
ارزيابى طيفسنجى مرئى و مادون قرمز نزديك در بر آورد مقادير فلزات سنگين سرب \\ و نيكل در خاك (مطالعه موردى: اراضى شهر رى) \\ رامين سميعىفرد ا* و حميدرضا متينفر

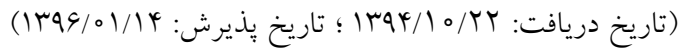

جكيده

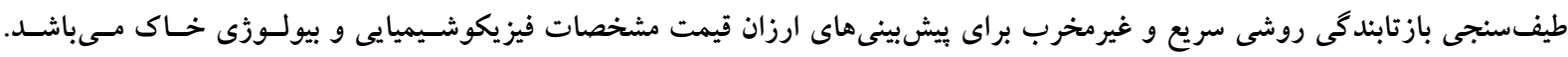

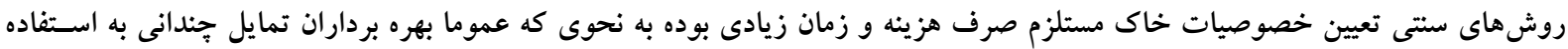

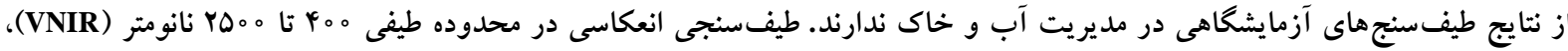

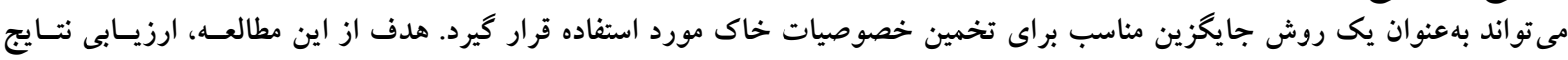

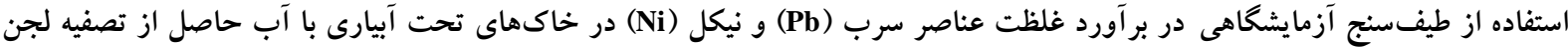

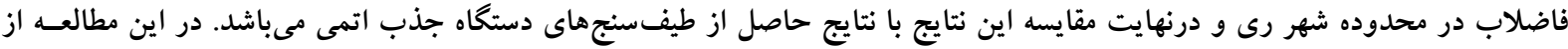

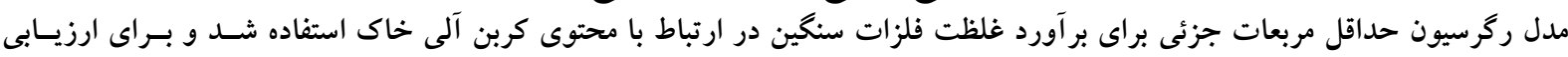

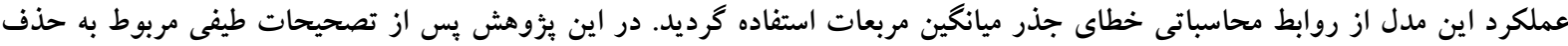

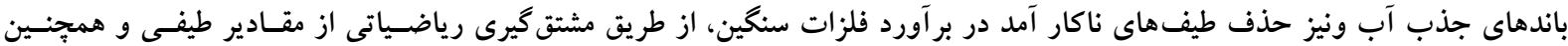

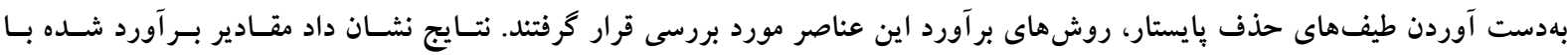

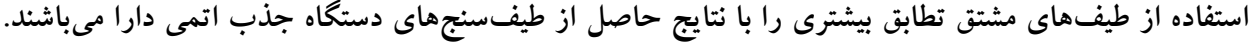

وازههاى كليدى: طيفسنجى انعكاسى، طيفسنجى جذب اتمى، فلزات سنخين، ركرسيون حداقل مربعات جزئى، مادون قرمز نزديكى و مرئى

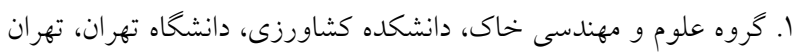
r. گروه علوم خاك، دانشكده كشاورزى، دانشكاه لرستان، لر ستان

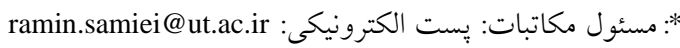


كميوست، آب آبيارى، آهك و ضايعات صنعتى به منـابع آب و

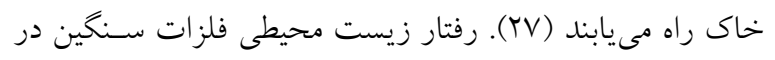

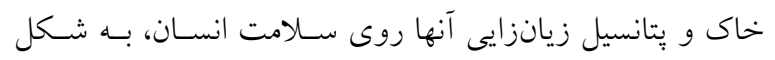

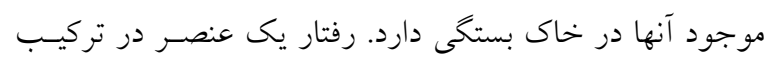
با محلول خـاك تحــرى آن را تحــت تـأثير قـرار داده و نهايتـاً

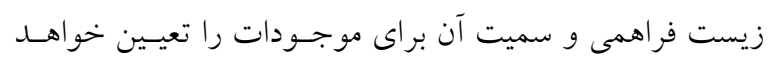

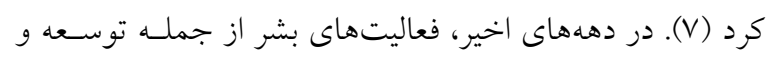

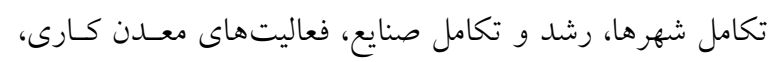

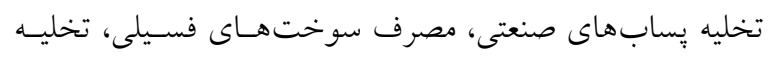

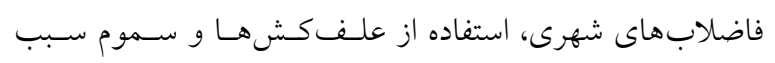

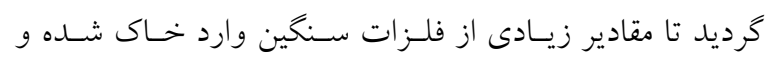

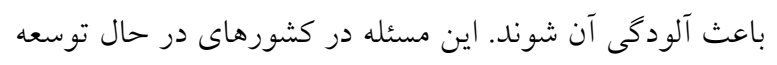

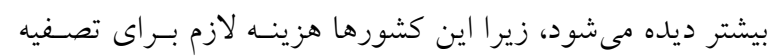

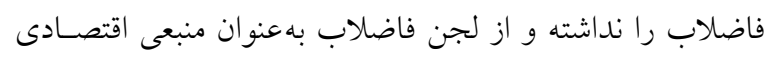

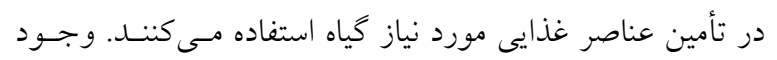

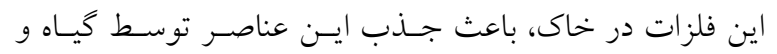

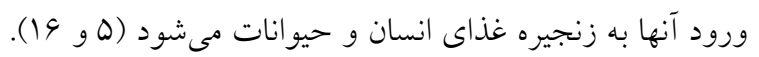

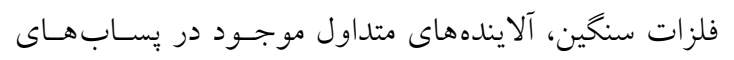

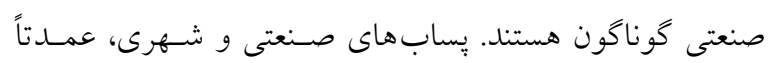

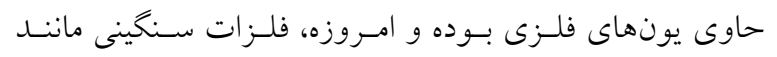

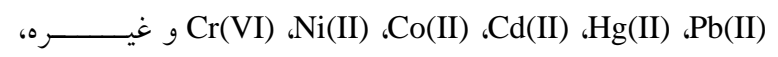

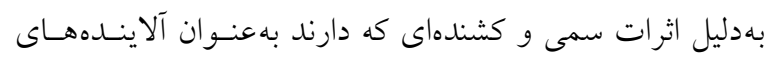

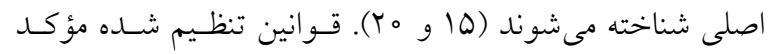

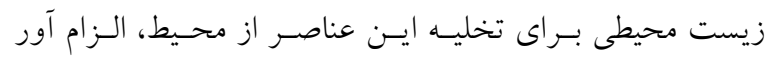

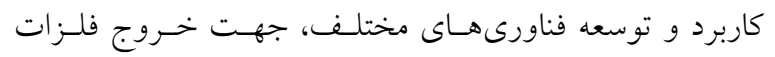

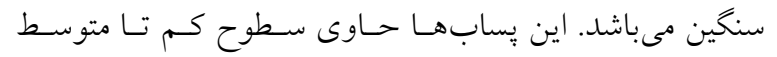

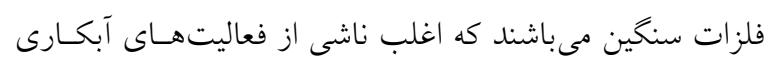

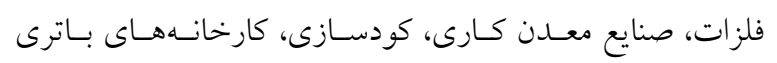

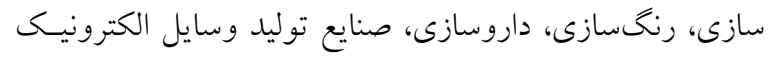

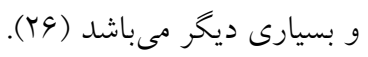

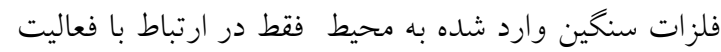

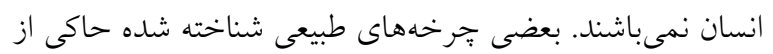

\section{مقدمه}

امروزه آلودكى خاكها به فلزات سنخين يكى از مشكلات رو به رشد، در سراسر جهان بوده و غلظت بيش از حد فلزات سنكين

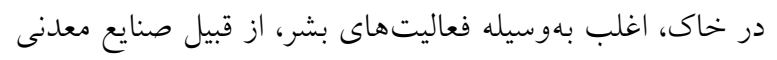

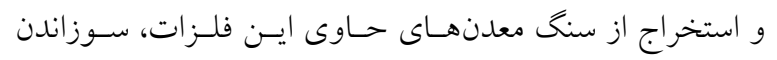

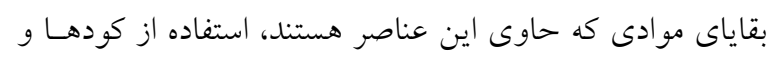

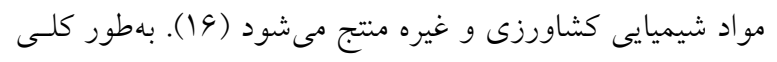

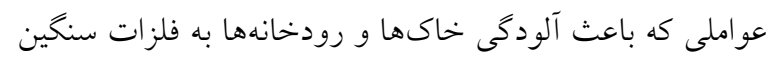

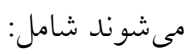
الف- يسابهاى حاصل از فعاليتهاى وسيع صنعتى.

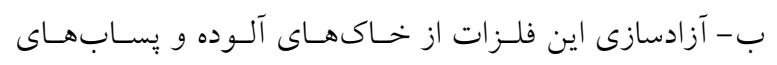
كشاورزى (آفت كشها، كودهاى شيميايى).

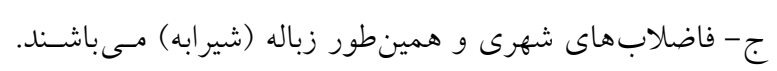

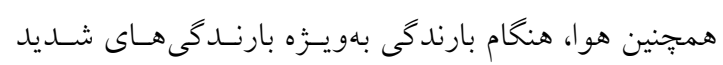

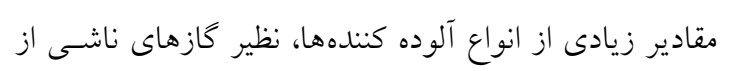

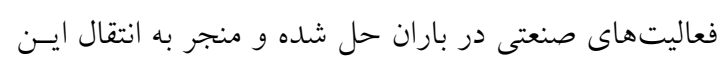

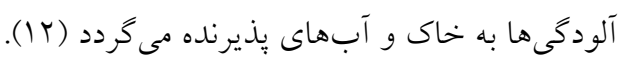

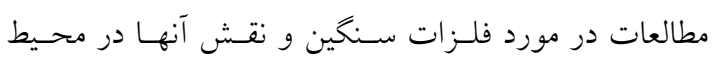

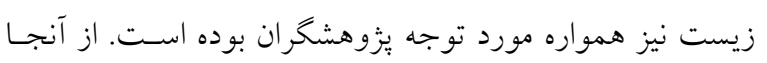

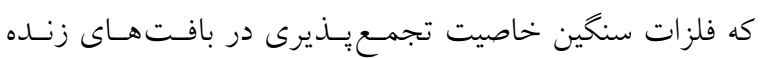

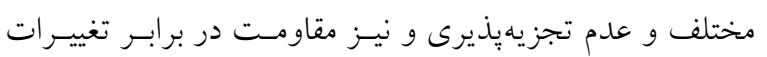

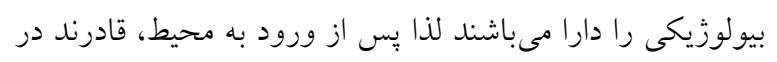

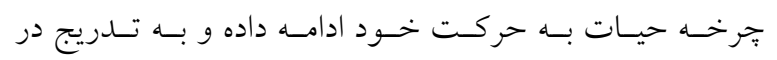

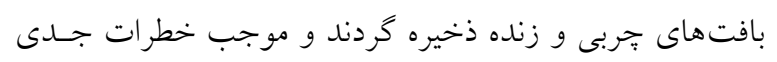

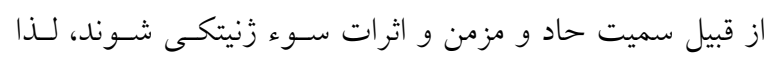

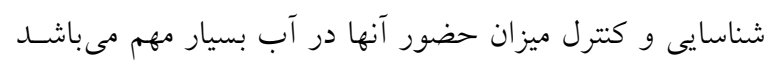

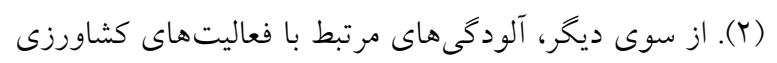

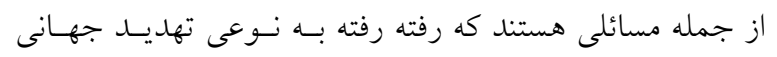

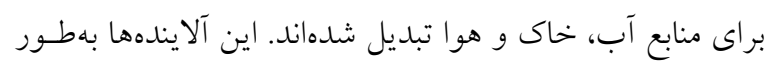

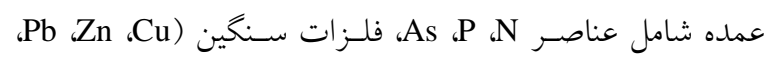

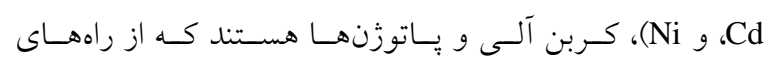

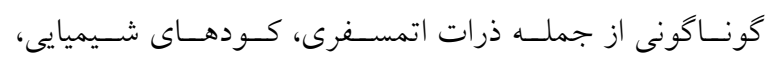


خاكهاى آلوده به اين نوع آلايندها را به نهادها و سازمانهـاى مربوطه ارائه كرد. بدون شكى شناسايى و مطالعهُ دقيـق منطقــه مـورد مطالعـه،

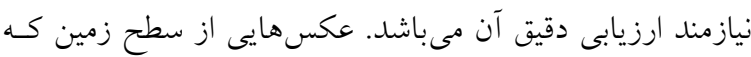

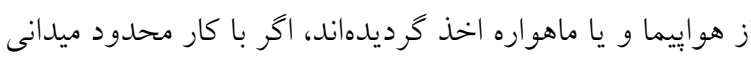
توأم باشند، مى توانند تصوير نسبتاً درستى از منطقه مورد مطالعه إنها توليد كنند (†). اساس كار سـنجش از دور مبتنى بـر شــناخت

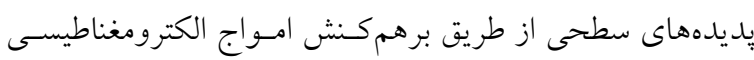

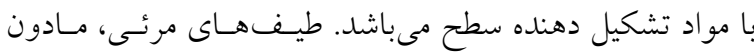

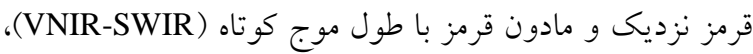

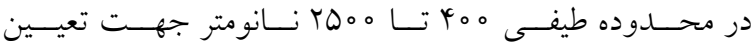

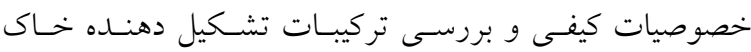

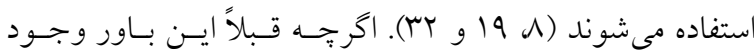

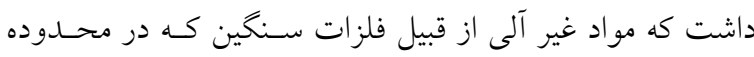

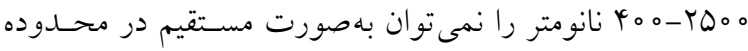

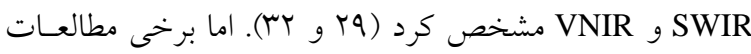

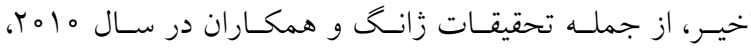

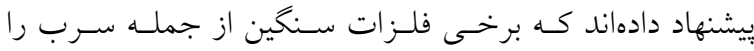
مى توان بهصـورت مستتقيم از ايسن طريـق تشـخيص داد (YY).

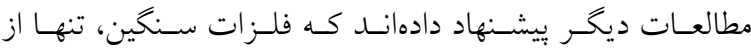

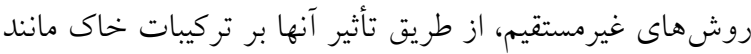

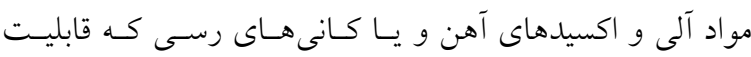

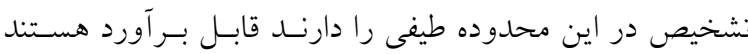

(r) (T)

هر عمليـات سـنجش از دور مفيـــ و كـارا، نيازمنــــ دانسش بايهاى و كافى از خصوصيات طيفى مواد مى باشد. بهطورى كـهـ

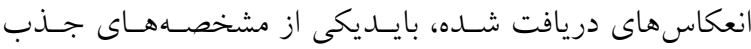

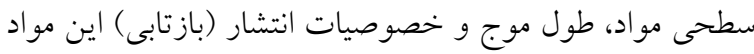
باشد (Tا و YY). تكنيكهاى سنجش از دور، تنها مى توانند لايه نازك و رويى خاك را به كمك سنجندها ها نشان دهند. بنسابراين،

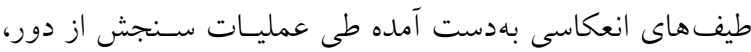
تحت تأثير بسيارى از فاكتورهايى هستند كـهـ ايـن فاكتورهـا در
آن است كه فلزات از سنخَها به خاك و سبيس به آب و تشكيل

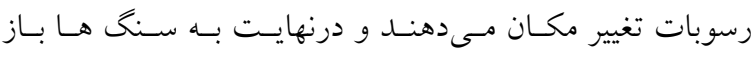

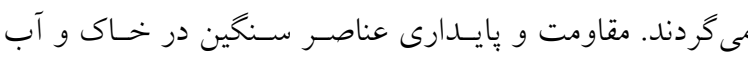

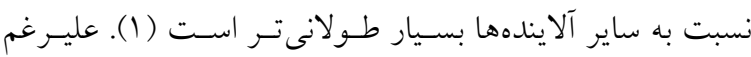

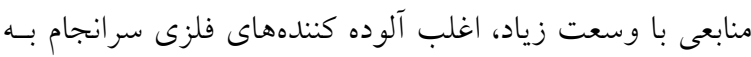

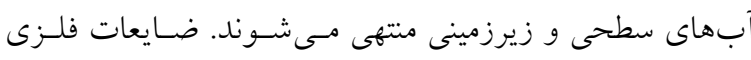

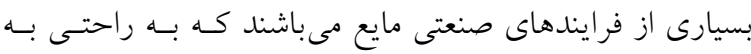

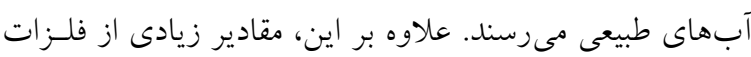

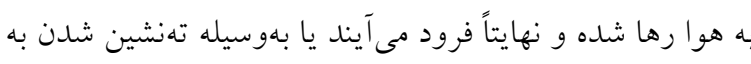

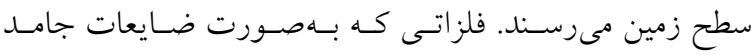

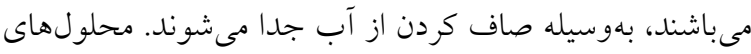

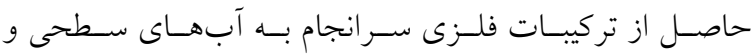
زيرسطحى مى ييوندند. بقاياى كشـاورزى و ضـايعات معـادن و

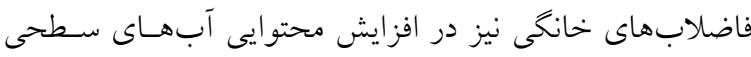
سهيماند (r). خاكهاى كشاورزى بهطور مستقيم و غيرمستقيم از طريق توليد غذا برروى سلامت عمومى تأثير مى كذارند، بنابراين

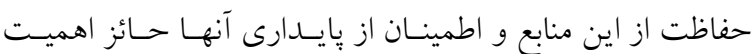
مى باشــ. يبشـرفت سـريع صـنعت و افـزايش رهاسـازى مـواد

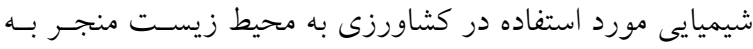

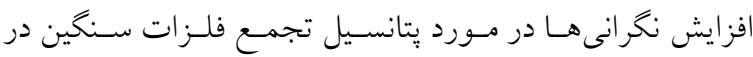

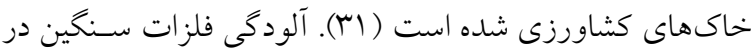
خاكهاى كشاورزى ممكن است منجر به بسىنظمى در سـاختار

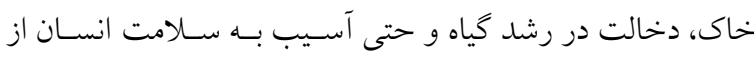
طريق ورود به زنجيره غذايى كردد (IV) با توجه به توضيحات و موارد ذكر شده در اين قسمت، اكر

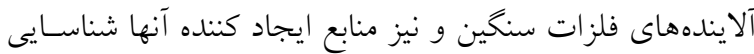
شود، مىتوان اطلاعات جامع و كاربردى در جهت كنتـرل ورود

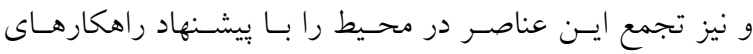

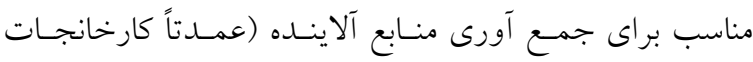

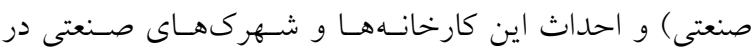
محلهاى مناسبتر، نظارت بيشتر بر روشهاى إن تصفيه فاضلاب

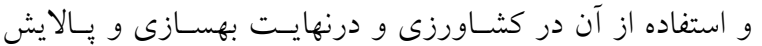




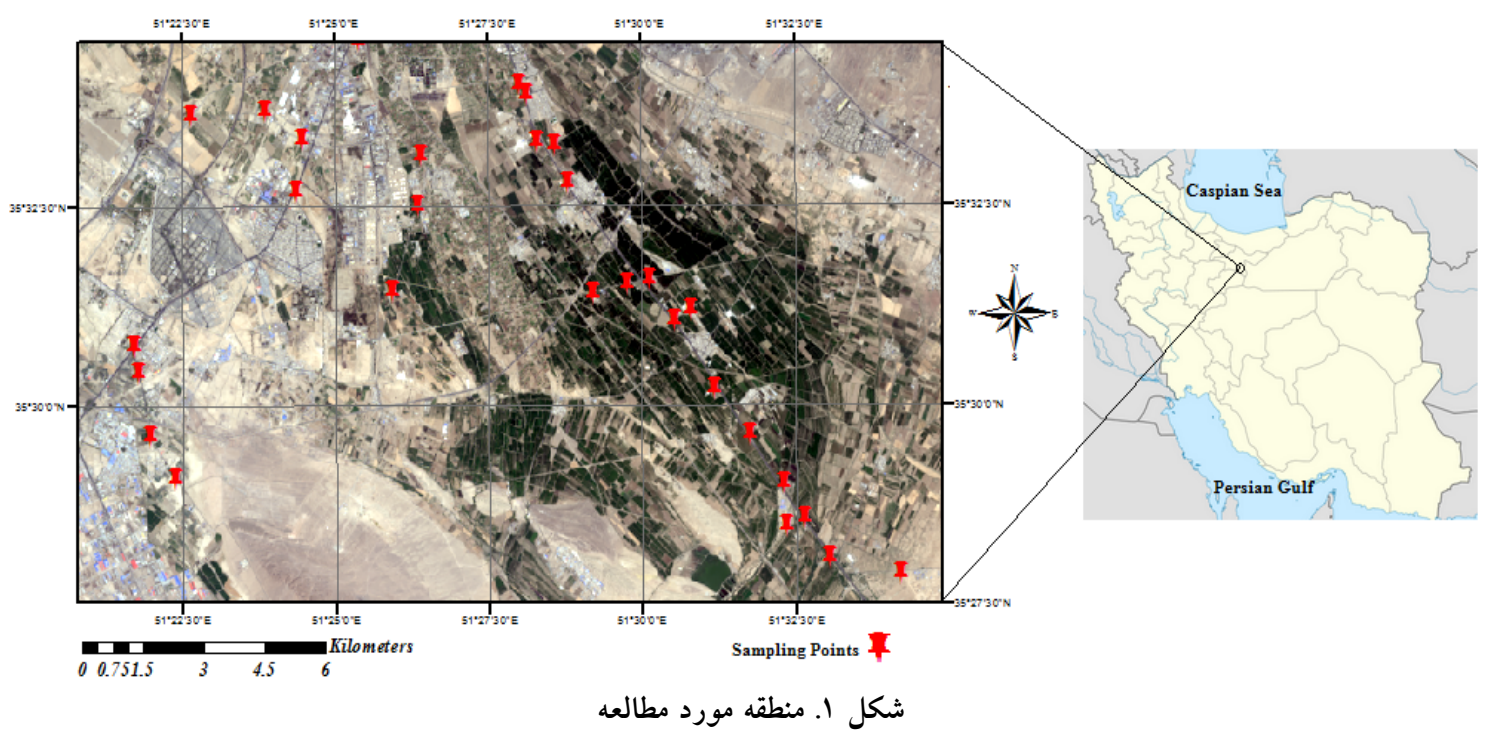

تشخيص آلايندگى فلزات سنخين و عناصر كميـاب آلاينـده در

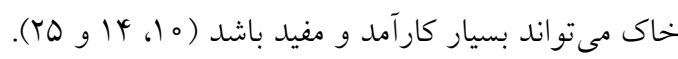

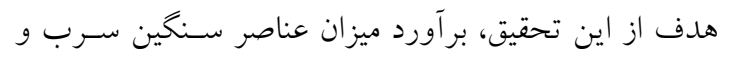

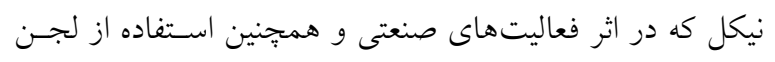

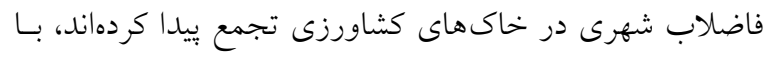

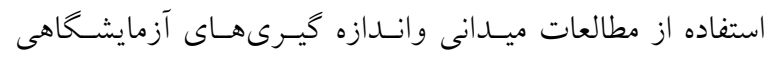

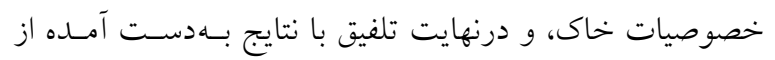

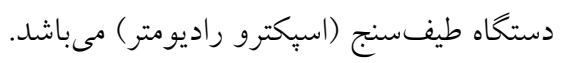

\section{مواد و روشها} منطقه مطالعاتى

يزوهش حاضر در منطقهاى در جنوب كلان شهر تهـران (شـهر

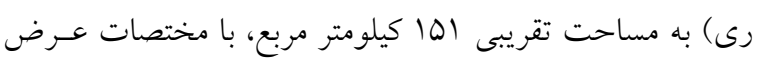

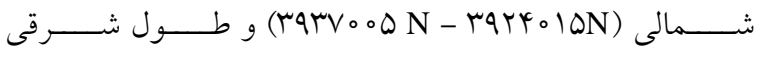

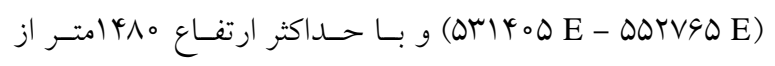
سطح دريا كه شامل بافتهاى شـهرى، صـنعتى و كشـاورزى و

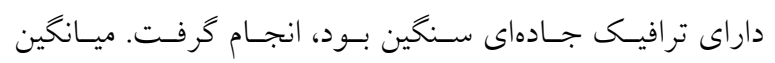
بارندگى سالانه اين منطقه ه 1 ماريلى متر و ميانخين دماى سـالانه

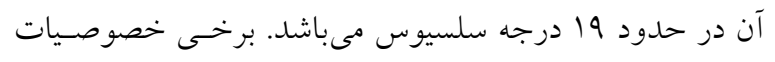

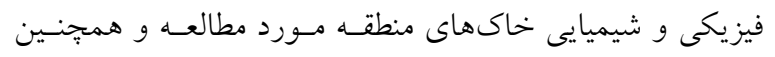

ارتبـاط بـا رطوبـت، مـواد آلى، تركيبـات مينر الـوزيكى (كـانى شناسى) و غلظت مواد در زمان اتخاذ دادهها مى باشند (9).

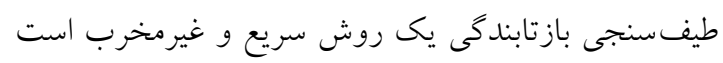

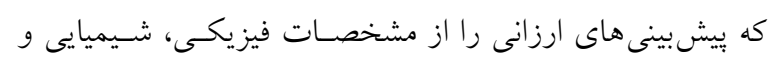

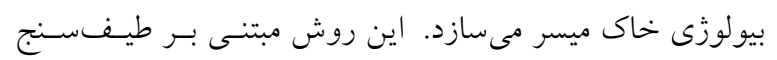

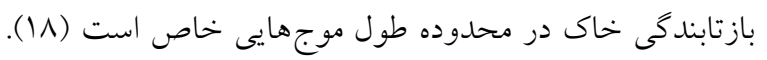

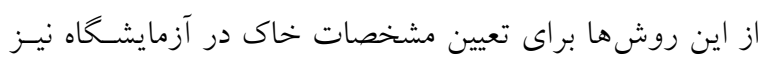

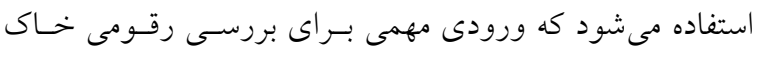

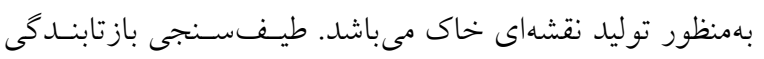

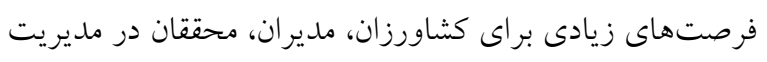
كيفيت خاك مهيا مى سازد (Yr)

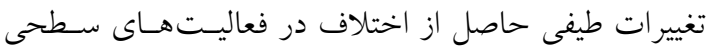

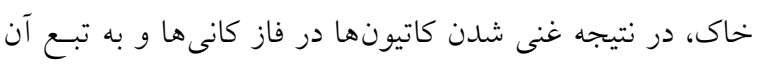

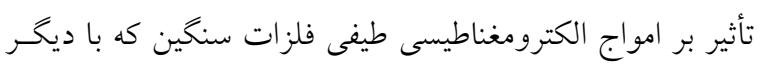

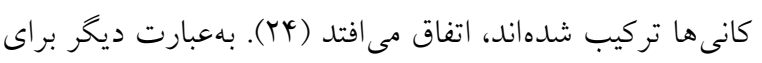

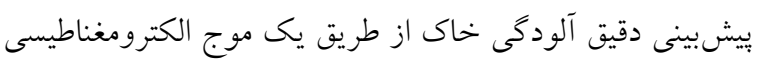

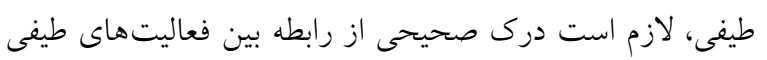

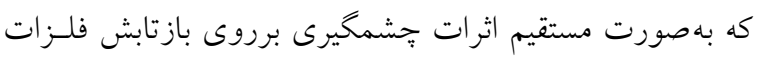

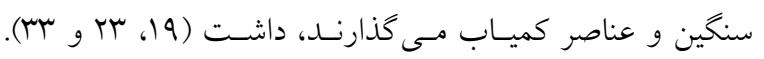
تحقيقات كذشته نشان دادهاند كه طيف مادون قرمز نزديك براى 
ارزيابى طيفسنجى مرئى و مادون قرمزنزيك در برآورد مقادير فلزات سنخين سرب ...

جدول ا. مختصات جغر افيايى منطقه مورد مطالعه و نتايج آزمايشخاهى خاكهاى نقاط نمونه بردارى

\begin{tabular}{|c|c|c|c|c|c|c|c|c|c|c|}
\hline (ميلى كرم در ليتر ) & (ميلى گرم در ليتر) & $\mathrm{pH}$ & بافت & سيلت & ر & شن & $\underset{\%}{\text { O.C }}$ & ras & مختصات & 3 \\
\hline$r \circ / V q 1$ & I/OMI & $V / 90$ & Si.C.L & $\Delta Q$ & MY & 11 & $1 / 14$ & 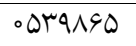 & ramerva & 1 \\
\hline IN/DYQ & $r / \circ \wedge V$ & $V / 4 y$ & Si.C & +1 & pr & IV & $1 / 49$ & ס & MarsAV。 & r \\
\hline IV/994 & T/OT & $V / A I$ & C & re & il & r & l/Ar & $\cdot \Delta r G \wedge \cdot \Delta$ & rampors & r \\
\hline$T Y / 011$ & $T / V \circ \Lambda$ & $V / V^{4}$ & C.L & ro & M & py & $1 / V 9$ & | & rarqov & $\varphi$ \\
\hline$r N / q \circ V$ & $r / \circ T_{0}$ & $V / I T$ & C.L & $\psi_{0}$ & rv & r & $1 / V 0$ & - DrGqTG & rqurvor & 0 \\
\hline$T V / O T Q$ & 1/or & $V / r r$ & Si.C.L & pr & ma & 19 & $1 / 01$ & - QRTAll & raraq4i & 9 \\
\hline$r G / T \circ Y$ & $1 / 1 \circ 4$ & $V / N_{1}$ & Si.C & rq & pr & 11 & $1 / \mu \wedge$ & - DYqQGK & raro. 49 & V \\
\hline Tr/O०Q & 1/NTO & $V / D Q$ & Si.L & or & 19 & rA & $0 / 9 \mathrm{~V}$ & -OKGOYA & raroNIV & $\wedge$ \\
\hline YN/AYI & $1 / 049$ & $V / l Y$ & $\mathrm{C}$ & rq & is & 10 & 1 & odrVIrq & rqrqool & 9 \\
\hline $10 / 094$ & $0 / 9 \circ 9$ & $\mathrm{~V} / \mathrm{AV}$ & C.L & iv & rv & YG & $1 / 11$ & - DFrOVG & rquvorq & 10 \\
\hline $9 / 090$ & $1 / 019$ & $V / D$ & Si.C.L & er & rq & 19 & $1 / 99$ & אד & rarvAFr & 11 \\
\hline$r 9 / 909$ & I/OTA & $V / 4 i$ & C.L & ty & M & ro & 1/94 & - DQIVTD & markvis & IT \\
\hline$r \circ / 0.9$ & 1/DFT & $V / \Psi \wedge$ & L & r & re & re & $1 / N$ & -DYAMKA & rqravq。 & r \\
\hline TV/OTY & $r / \mu \circ \Lambda$ & $V / \wedge 9$ & Si.C.L & r & rv & ro & $1 / M$ & oDrural & rqurv & 14 \\
\hline IT/VAY & $T / 09 V$ & V/ar & C.L & rv & سח & TY & $1 / 01$ & . DFTISV & rqMYGrV & 10 \\
\hline$\mu Y / \circ V \Lambda$ & & V/AT & C.L & rᄉ & ऍ & My & $r / r q$ & oDrrqIF & rqrqul。 & 19 \\
\hline $10 / 4 \Delta \Lambda$ & Mat & $\mathrm{V} / \wedge \Delta$ & C & rq & io & rq & $\circ / \mathrm{VI}$ & - DrG० rq & rNTQYIN & IV \\
\hline TM/TrQ & $r / \circ \circ \Delta$ & V/OT & Si.C.L & ky & rV & 19 & 1/V9 & oDMFiNK & rqTorıq & 11 \\
\hline ID/TYN & o/VA & $V / \mathbb{A} V$ & $\mathrm{C}$ & r人 & r & 19 &.$/ 94$ & ODFTVTG & rarksql & 19 \\
\hline $\mid \psi / A V q$ & -/AVG & $V / 01$ & C.L & 41 & ו & rA & $\circ / \wedge 1$ & 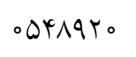 & rqroN०r & ro \\
\hline rT/rGY & $r / q 41$ & $V / A Y$ & L & \&l & rI & r & $1 / 91$ & - DFYQAD & rqrvq11 & YI \\
\hline re/04G & I/VFA & $V / 91$ & C.L & rq & rA & سח & Y/IV & - DYQYaR & ram & rT \\
\hline $19 / 140$ & $r / 01 Y$ & $\mathrm{~V} / \mathrm{Vq}$ & Si.C.L & Q. & rV & r & $1 / \circ 0$ & - DFYYADQ & rqrovq。 & r \\
\hline $19 / 40 V$ & 1/4Ts & $V / G 4$ & Si.C.L & $\uparrow \wedge$ & ra & 19 & $1 / D F$ & ODKY. GG & rarulor & MY \\
\hline TV/AQV & 1/OrT & $\mathrm{V} / \mathrm{M}$ & C & ro & D. & 10 & $1 / 49$ & $.0 r q 19$. & TqMITIV & ro \\
\hline $19 / 9 \circ r$ & lyky & V/VG & $\mathrm{L}$ & re & rr & ro &.$/ 94$ & -OHTAII & raraq4i & rG \\
\hline $18 / 019$ & $0 / A V I$ & V/Ar & C.L & rq & rV & TY & $T / T$ & ०OKNIOr & rqM rar & TV \\
\hline Tr/T & $r / 001$ & $V / 09$ & Si.C & ty & 41 & 10 & $1 / 1$ & 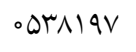 & rqqoqkT & YA \\
\hline$\Lambda / 0 \mid r$ &.$/ 991$ & $V / 91$ & Si.C.L & is & rq & 10 & l/Ar & - DrNHKG & rqMV०Dr & rq \\
\hline$Y Y / Y Q S$ & $1 / \circ \circ \wedge$ & V/Ar & L & r & r & pq & $1 / 4 t$ & 。 OrqVAr & & $\mu_{0}$ \\
\hline $1 \% / 9 V 4$ & $r / 040$ & $\mathrm{~V} / \mathrm{AY}$ & C.L & py & ه & YI & $1 / 9 V$ & oDfFiro & rqulto。 & ו \\
\hline YQ/AVT & $1 / 901$ & $V / 4 q$ & C & ro & pr & Tr & $1 / 09$ & DOFTYGI & rarsooq & Tr \\
\hline rV/AqY & $r / \circ V q$ & $V / 94$ & C.L & $\uparrow \wedge$ & $\mu_{0}$ & Yr & $r / \circ Y$ & oDFYagr & rquifit & سM \\
\hline$|N / V q|$ & $1 / T V Y$ & $\mathrm{~V} / \mathrm{Al}$ & Si.C & 41 & 41 & 11 & $1 / 11$ & ODFGIKK & rar.090 & My \\
\hline $11 / r 91$ & $1 / 110$ & $V / 90$ & C & My & Gr & TY & $1 / 1 T$ & 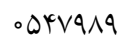 & rarvarl & o \\
\hline rT/QTG &.$/ 9 \mathrm{VV}$ & $\mathrm{V} / \mathrm{VI}$ & C.L & rq & My & TV & $1 / M$ & oDYqRKF & raroqV。 & ma \\
\hline
\end{tabular}

مختصات جغرافيايى آنها در جدول (1)، آورده شده اسـت. رده موسسه تحقيقات خـاك و آب كشـور طبـق سيستم ردهبنـىى

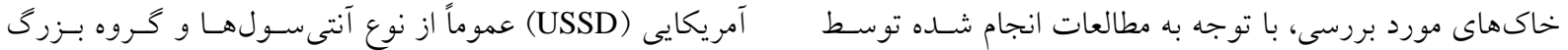




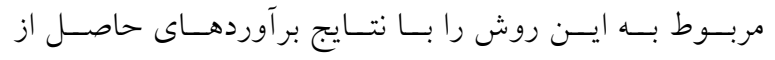

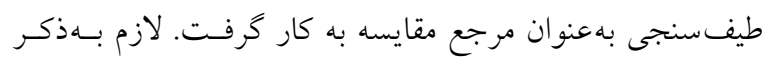

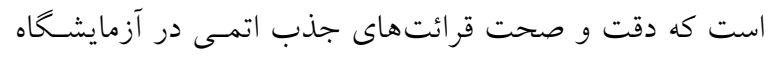

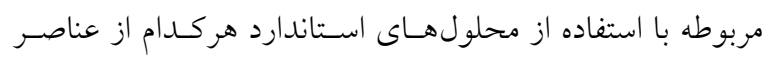

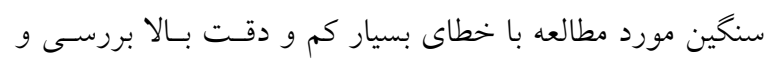

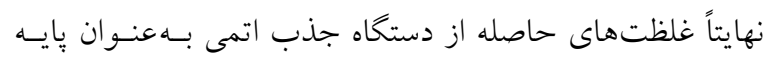
مطالعات انتخاب كرديد.

\section{طيفسنجى هاى آزمايشخاهى}

يس از انجام تجزيه و تحليل هاى ياد شده، نمونهــاى باقيمانــده

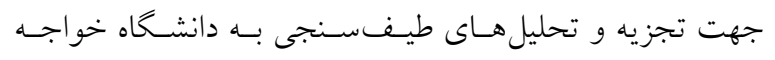

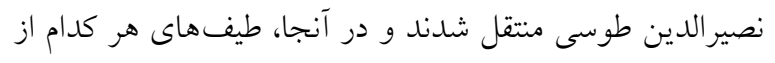

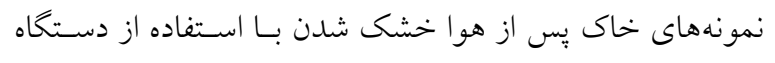

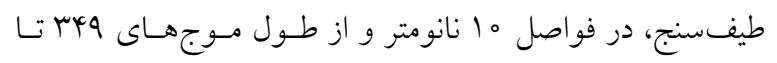

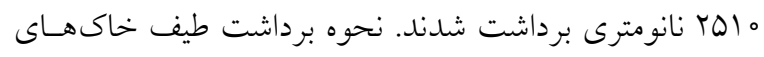

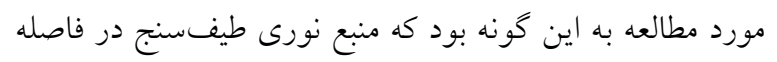

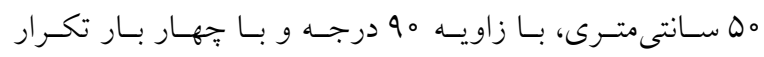

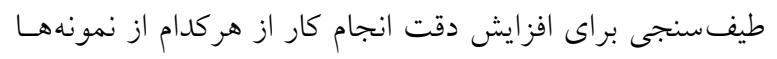

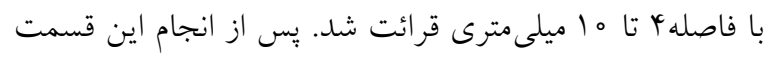

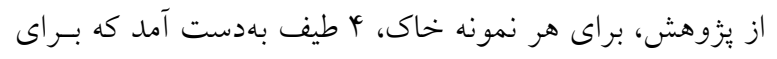

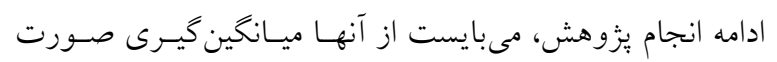

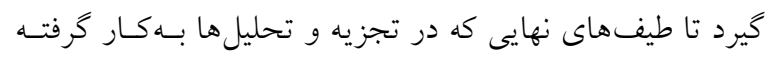

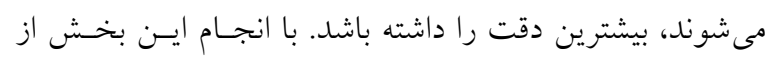

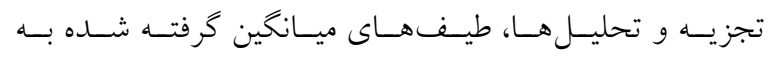

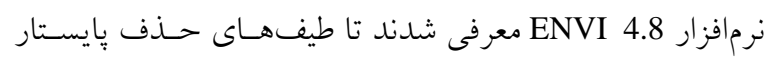

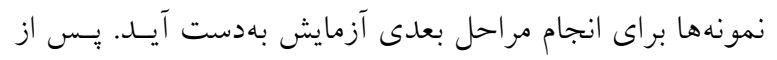

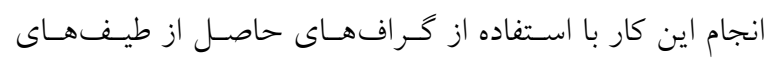

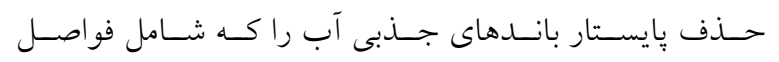

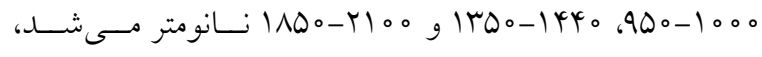
حذف شد تا طيف هاى نهايى براى انجام تجزيه و تحليـلهـاى

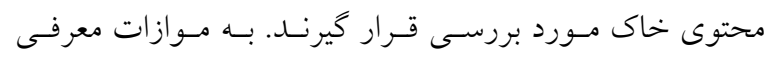

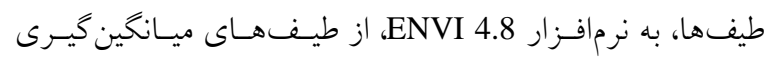

تورى اورتنت مىباشد كه درواقع آنتى سولهاى منـاطق خشـى

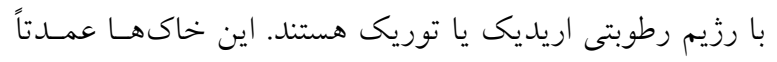

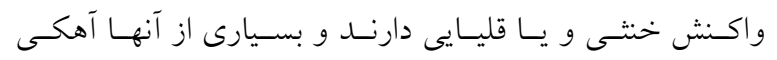
مى باشند.

\section{تعيين ميزان عناصر سنگين با استفاده از دستخاه جذب اتمى}

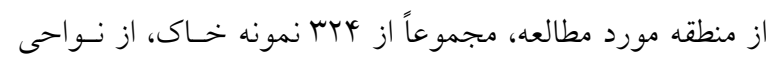

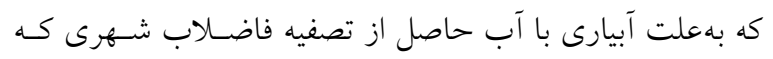

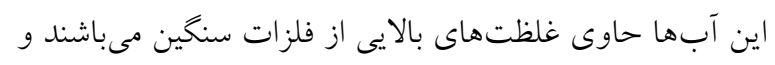

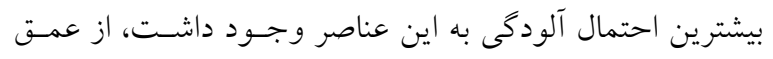

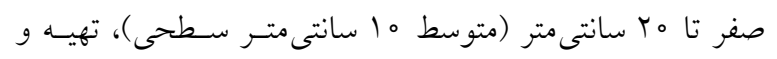

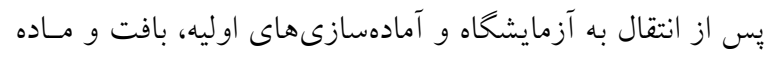

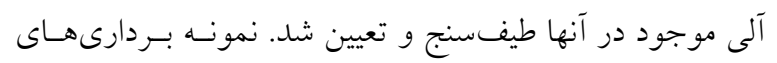

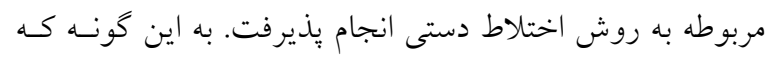

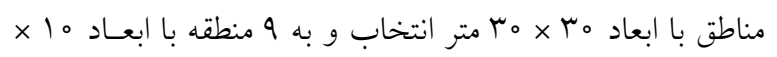

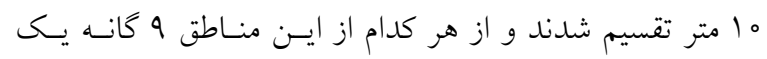

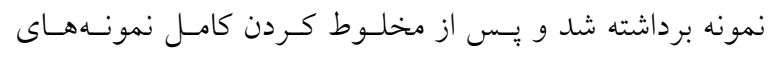

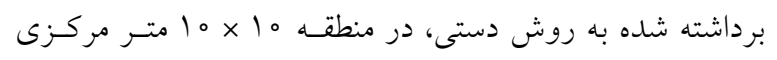

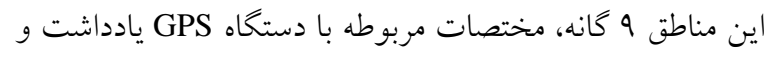

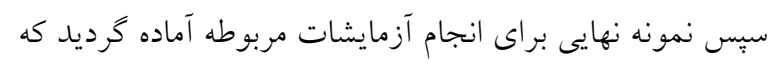

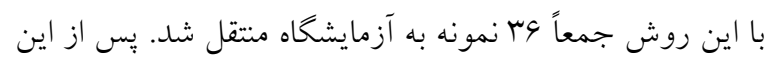

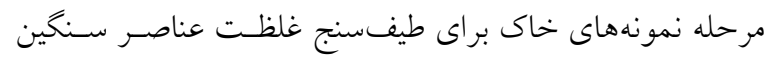

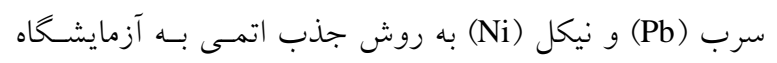

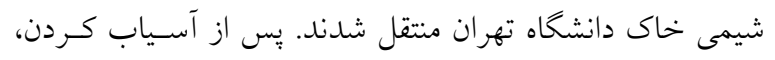

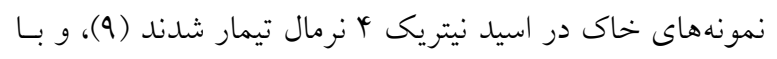

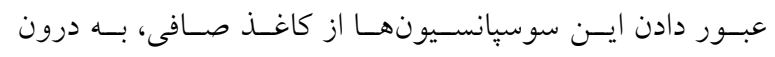

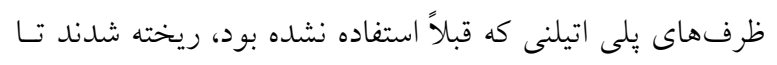

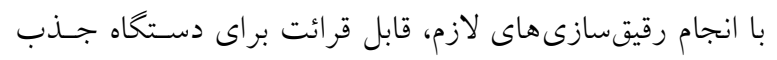

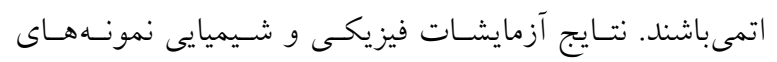

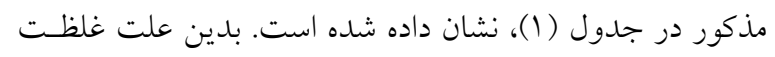

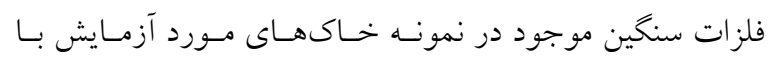

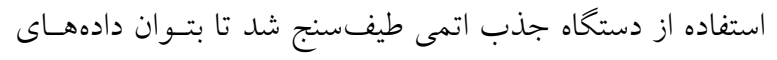


اعتبارسنجى دادهها

در اين مطالعه براى ارزيابى عملكرد مــل از روابـط محاسباتى

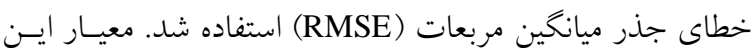
روش بر بايه مقايسه بين مقادير بيشبينى شده و مشـاهده شـده

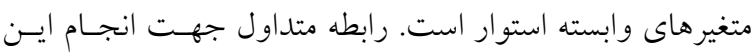
نوع اعتبارسنجى بهصورت معادله (4) تعريف مى مشود. RMSE $=\sqrt{\frac{\sum_{\mathrm{i}=1}^{\mathrm{n}}\left(\mathrm{Y}^{(\mathrm{pre})}-\mathrm{Y}^{(\mathrm{obs})}\right)^{\gamma}}{\mathrm{n}}}$

در اين رابطه n برابـر تعـداد نمونسههـا و مقــادير Y(pre) و بهترتيب مقادير بيشبينى شده و طيفسنج شده (مشاهده شـده) متغيرهاى وابسته هستند. از طرف ديكر R بهترين ارتبـاط بـين

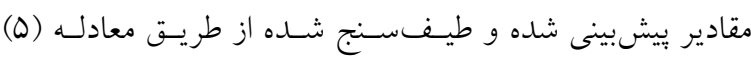

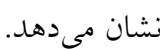
$\mathrm{R}^{r}=1-\frac{\mathrm{SS}_{\text {res }}}{\mathrm{SS}_{\text {tot }}}$

$\mathrm{SS}_{\text {res }}=\sum_{\mathrm{i}=1}^{\mathrm{n}}\left(\mathrm{Y}^{(\mathrm{pre})}-\mathrm{Y}^{(\mathrm{obs})}\right)^{\mathrm{r}}$

$\mathrm{SS}_{\text {tot }}=\sum_{\mathrm{i}=1}^{\mathrm{n}}\left(\mathrm{Y}^{(\mathrm{obs})}-\overline{\mathrm{Y}}\right)^{r}$

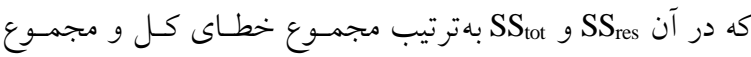
خطاى ركرسيون و

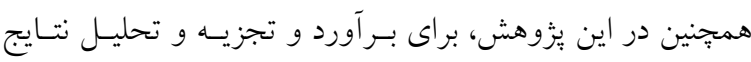
آزمايش از نرمافزارى آمارى (MATLAB) استفاده مىشوده.

\section{نتايج و بحث}

همانطور كه كفته شـــ هـــف از ايـن مطالعه، ارزيـابى نتـايج

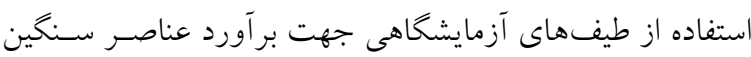

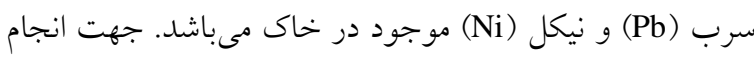

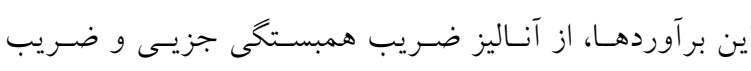
همبستخى ييرسون استفاده شده است. در بخش اول آناليز اوليـه ودئ

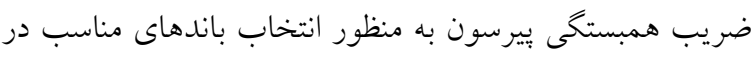
محيط SPSS صورت يذيرفت. باتوجسه بـه تعـداد كب نمونسه و تعداد زياد باندهاى طيف آزمايشكاهى، اسـتفاده از مــدل PLSR

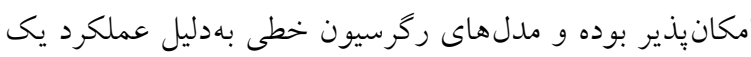

شده كه باندهاى جذب آب آنها حذف شده بود، مشـتق گرفتـه

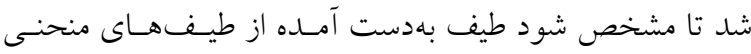

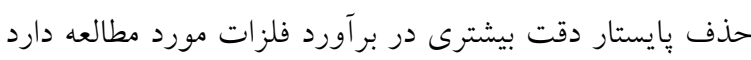

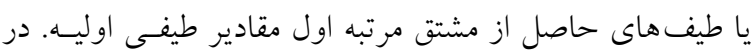

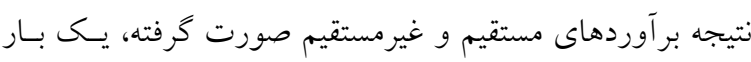

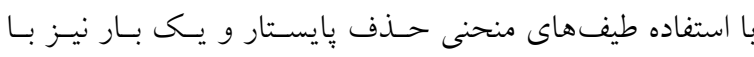

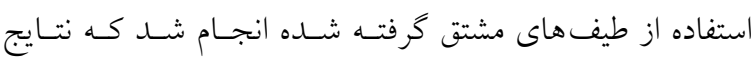

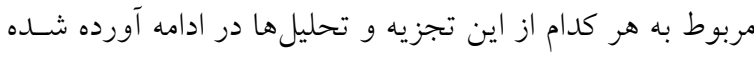

\section{مدل حداقل مربعات جزئى (PLSR)}

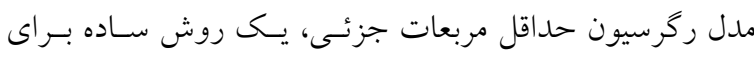

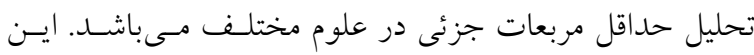

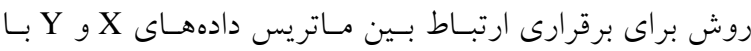
استفاده از يك مدل جند متغيره خطى استفاده مى شود. همجنَسين اين روش بهتر از مدلهاى رخرسـيونى ديخـر عمـل مسىنمايسـ.

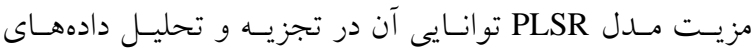

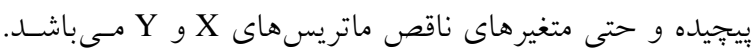

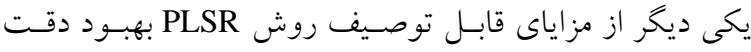

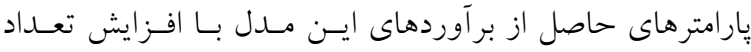

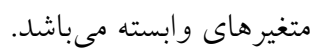
$\mathrm{Y}=\mathrm{X} \cdot \mathrm{b}+\mathrm{E}$

كه در آن Y : متغير برآوردشده (در رخرسيون PLSR) در شكل

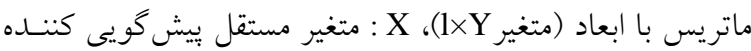

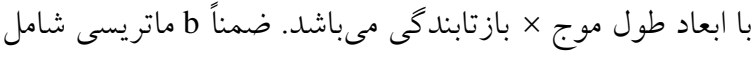
ضر ايب رخرسيون و E ماتريسى از خطاهاى باقىمانده است.

$\mathrm{X}_{\mathrm{nk}}=\sum_{\propto=1}^{\mathrm{f}} \mathrm{t}_{\mathrm{n} \propto} \cdot \mathrm{P}_{\propto \mathrm{k}}+\mathrm{E}_{\mathrm{nk}}$

$\mathrm{Y}_{\mathrm{mk}}=\sum_{\propto=1}^{\mathrm{f}} \mathrm{u}_{\mathrm{m} \propto} \cdot \mathrm{q}_{\propto \mathrm{k}}+\mathrm{F}_{\mathrm{mk}}$

كـه در آن t و بردارهـاى امتيـاز، P و q بردارهـاى اختيـارى

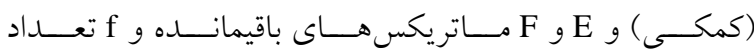

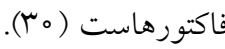


نشريه علوم آب و خاك (علوم و فنون كثاورزى و منابع طبيعى) / سال بيست و يك / شماره جهار / زمستان وج\|

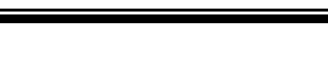

\begin{tabular}{|c|c|c|c|}
\hline $\mathrm{Pb}$ & $\mathrm{Ni}$ & O.C & \\
\hline ०/ MG八* & $\circ / 4 \circ V^{*}$ & 1 & Pearson Correlation \\
\hline \%/OYV & $0 / 014$ & - & Sig. (Y-tailed) \\
\hline re & re & ma & $\mathrm{N}$ \\
\hline
\end{tabular}

ئزوهش از طيفهاى مربوط به كربن آلى خاى در بـر آورد فلـزات سنخين مورد مطالعه استفاده كرديد.

بررسى يُتانسيل باندهاى طيف آزمايشعاهى با وابستخى بـالا

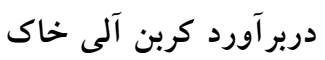

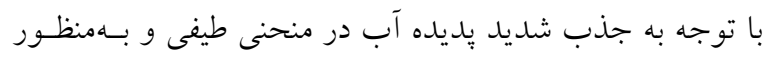

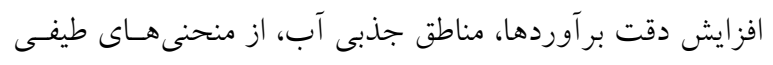

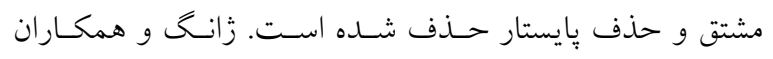

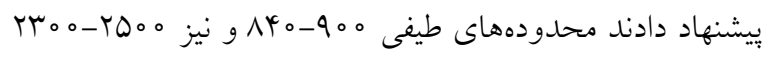

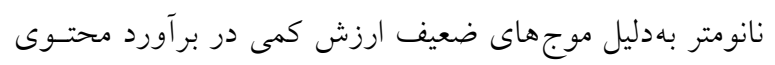

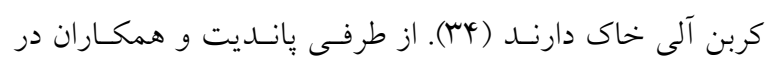

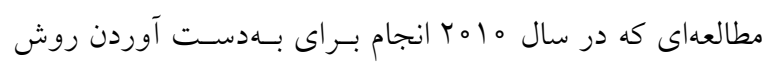

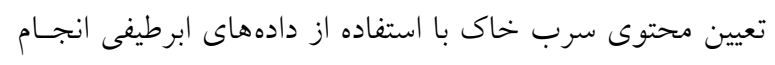

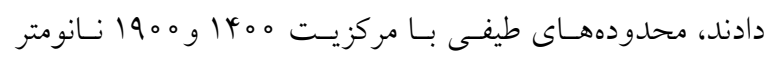

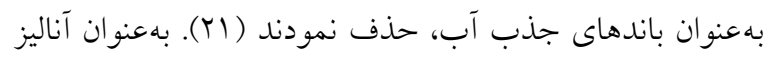

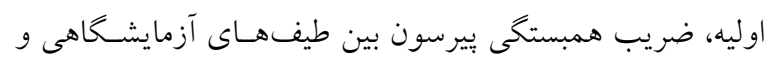

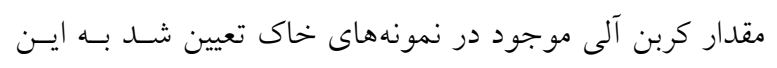

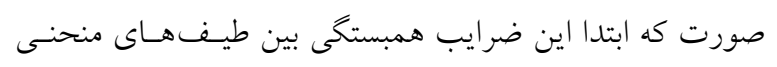

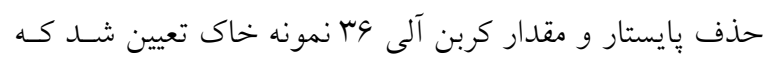

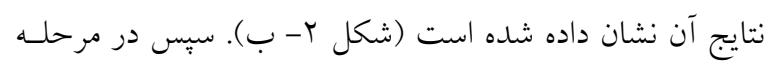

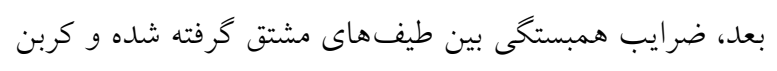

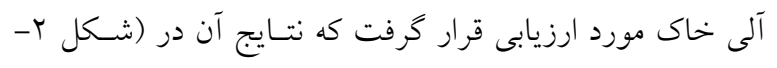

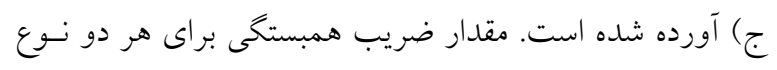

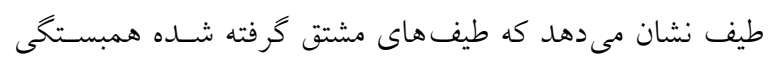

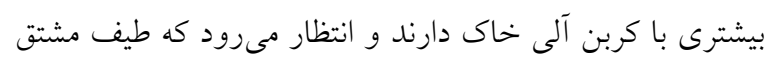

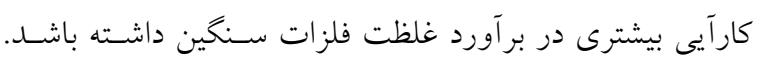

به يك معادلات كمترين مربعـات و زمـان بـالاى قيـادهسـازى، مدلهاى غير خطى استفاده نمى شوند.

بر آورد عناصر سنگين با استفاده از تجزيه و تحليلهاى طيفى و كربن آلى خاى در جدول (Y) همبستخى بين كربن آلى خاك با عناصر فلزى سرب

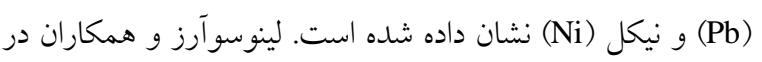

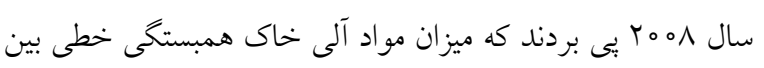

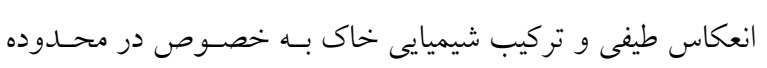

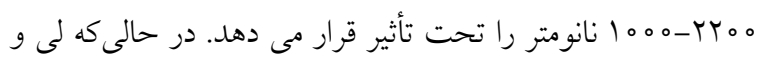

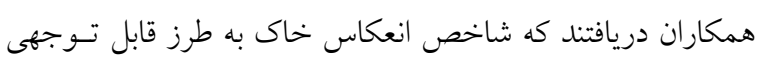
تحت تأثير دانهبندى خاى قرار دارد. كليسون و همكاران در سـال

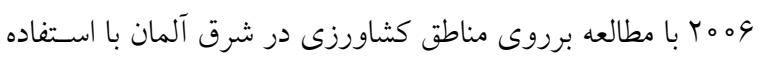

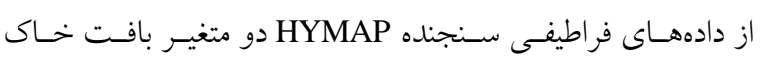

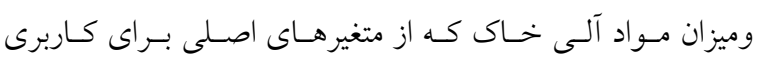

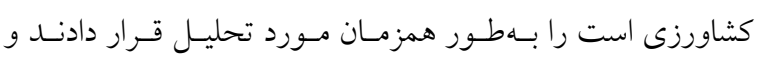

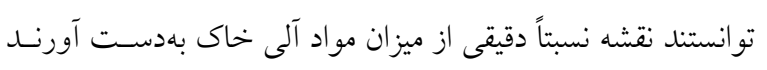

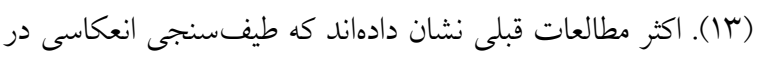
محدودههاى مادون قرمز و مرئى بـراى تشـخيص مقــادير فلـزات

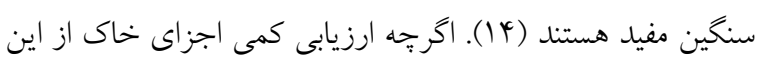

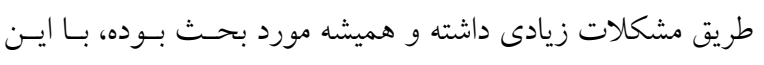

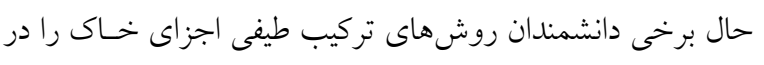

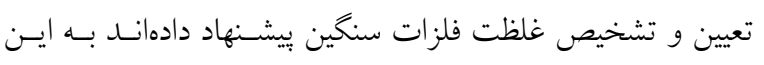

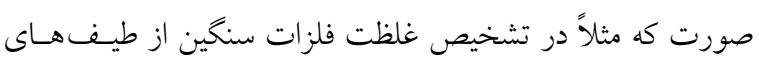

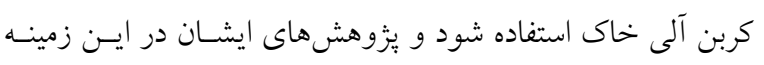

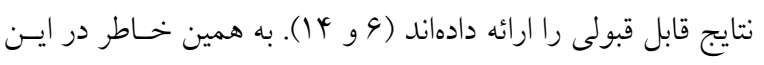




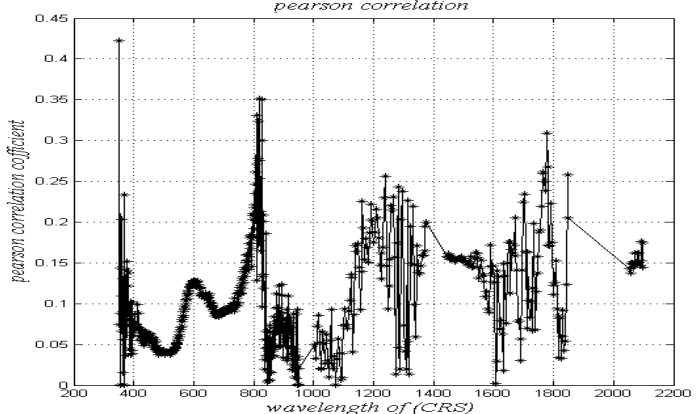

(U)

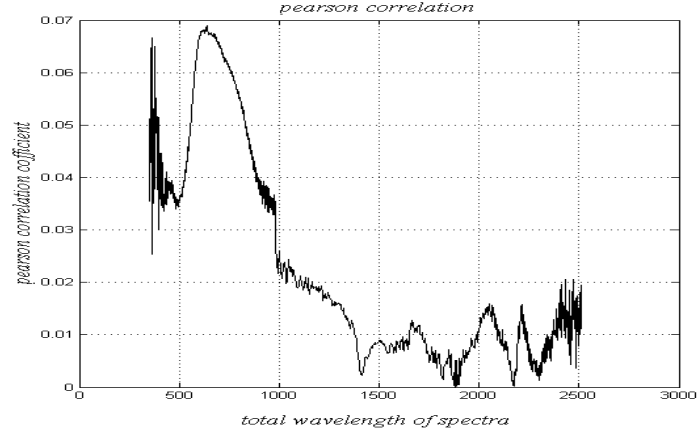

(الف)

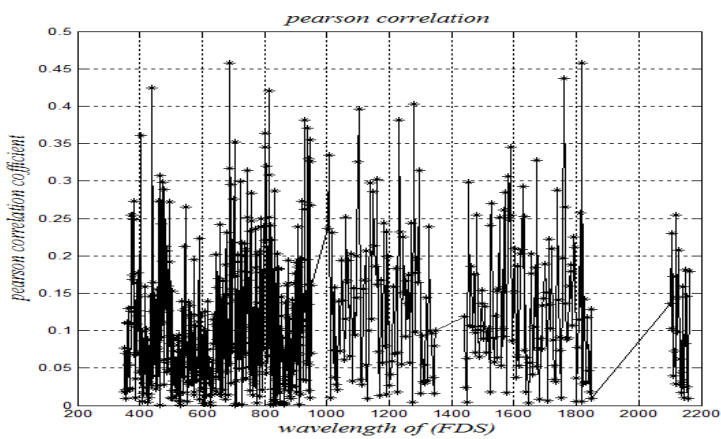

(ج)

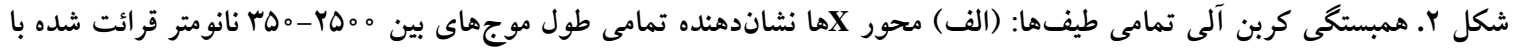
استفاده با دستخاه طيف سنج و محور YY ضريب همبستگى بين غلظت عناصر مورد مطالعه و طيفهاى قرائت شده مىباشد، (ب) طيف منحنى حذف يا يستار يس از حذف باندهاى جذب آب و (ج) طيفهاى مشتق بِ از حذف باندهاى جذب آب

جدول ب. مقايسه كار آيى طيفهاى منحنى حذف يايستار و طيفهاى مشتق گرفته شده در برآورد كربن

\begin{tabular}{|c|c|c|c|c|}
\hline RMSE(ميلى گرم در ليتر) & $\mathrm{R}^{r}$ & فاكتور بهينه & تعداد باند مؤثر & طيف \\
\hline ( ) & ( & $\wedge$ & ir & Continuum removal \\
\hline $0 / 19$ & $\circ / \wedge V$ & 11 & TQ & DIFF \\
\hline
\end{tabular}

DIFF طيفهاى مشتق كرفته شده از كل طيفهاى آزمايشگاهى يس از حذف باندهاى جذب آب مىباشد

فاكتور مناسب ميزان تغييرات كم RMSE دادههـاى آنـاليز شـده مىباشد. در اين بخش تعداد فـاكتور بــا تغييـرات خطـا نـاجيز، بهعنوان فاكتور بهينه انتخاب مسى شـود (شـكل r و جــدول r). همجنين تعداد فاكتور بهينه از آناليز باقيماندهها تعيين مى گـــدد. در صورتى كه نمـودار بيراكنـدكى خطـاى نمونـهـهـا نسـبت بــه احتمال فراوانى تجمعى، تشكيل يك خط مسـتقيم بدهــ نشـان مىدهد خطاها از تابع توزيع نرمال كه فرض اساسى حل مدلها است، تبعيت مى كنند. همانطـور كـه در شـكل (Y)، نشـان داده
جرا كه اين طيف ها باندهاى موثر و به دنبال آن بانـدهاى بهينـه بيشترى را براى برآورد كربن آلى در اختيار ما قرار مسىدهنـد و نتايج مربوط به R و همجنين RMSE حاصل از آن در جــدول

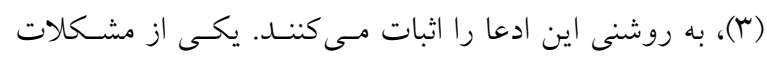
عمده استفاده از مدل كمترين مربعـات جزيسى، انتخـاب تعـداد فاكتور مناسب مىباشد. فاكتورهـاى ايـن مــل براسـاس آنـاليز مولفههاى اصلى تعيين شده بنابراين فاكتورهـاى ابتـدايى داراى بيشترين اطلاعات مىباشند. يكسى از معيارهــاى انتخــاب تعـداد 

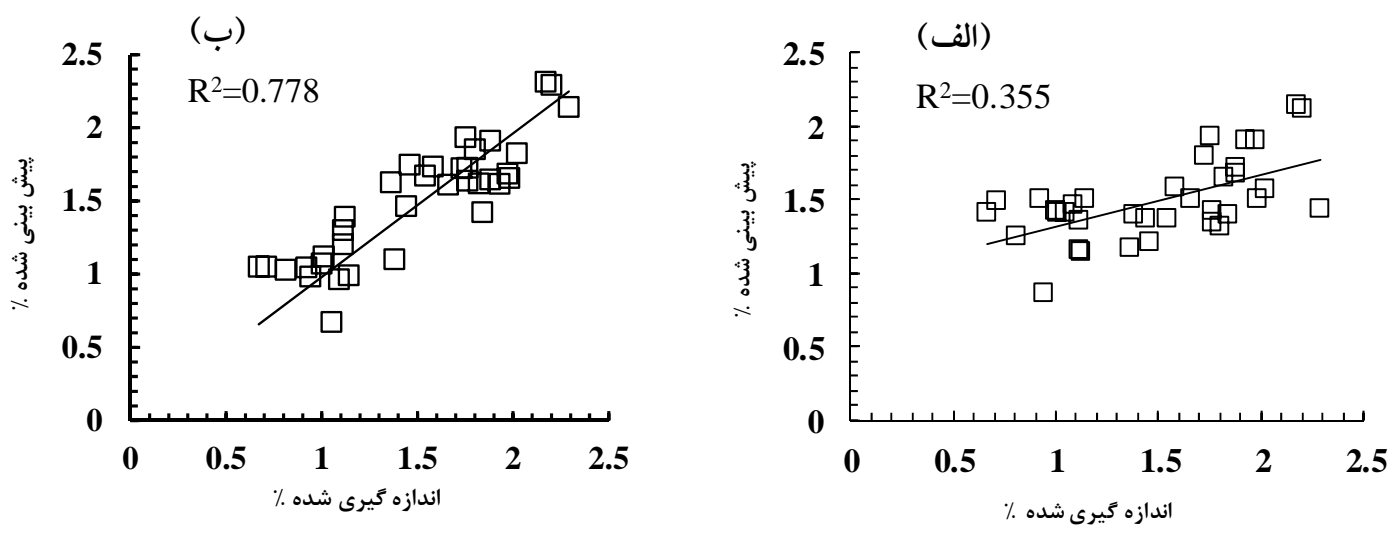

شكل r. مقايسه مقادير بيشبينى شده كربن آلى خاك توسط الف) طيف منحنى حذف بايستار و ب) طيف مشتق با مقادير واقعى كربن آلى

\begin{tabular}{|c|c|c|c|c|}
\hline \multicolumn{2}{|r|}{ طيف مشتق } & \multirow[b]{2}{*}{ رابطه رياضى } & \multicolumn{2}{|c|}{ طيف منحنى يايستار } \\
\hline $\mathrm{R}^{r}$ & RMSE(ميلى گرم در ليتر) & & RMSE(ميلى گرم در ليتر) & $\mathrm{R}^{r}$ \\
\hline o/NY & $0 / 14$ & $\mathrm{Ni}=(0 / 99 \wedge *(\mathrm{O} . \mathrm{C}))+0 / 949$ & $0 / \pi$ & \%/Ar \\
\hline.$/ 94$ & $1 / 09$ & $\mathrm{~Pb}=(\Delta / \mu G V *(\mathrm{O} . \mathrm{C}))+1 \Gamma / 0 Y$ & $1 / 09$ &.$/ 9 r$ \\
\hline
\end{tabular}

دادند. نحوه بِراكنش كربن آلكى بــرآورد شــده در مقايسـه بـا مقـادير طيفسنج شده اين مواد در شكل (r) (الف و ب) نشـان داده شـده

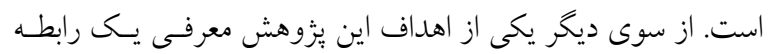

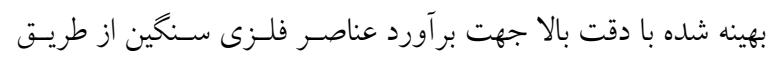

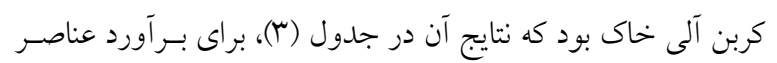

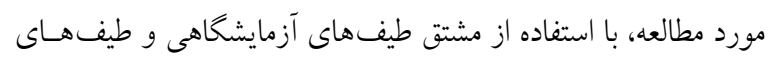

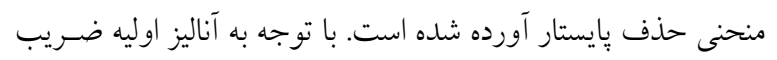

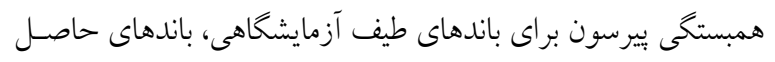

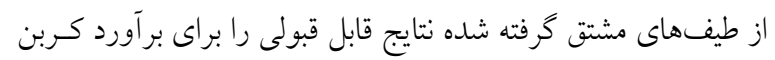

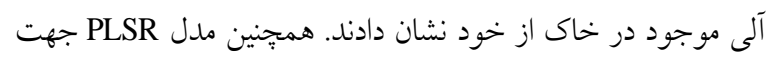

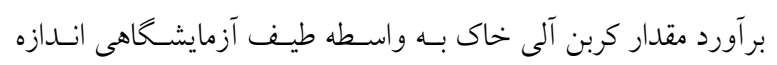

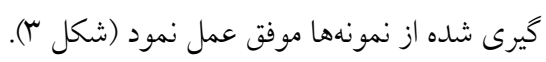

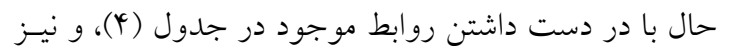

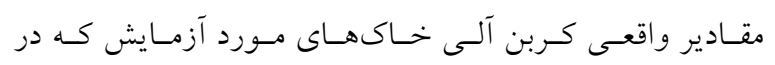

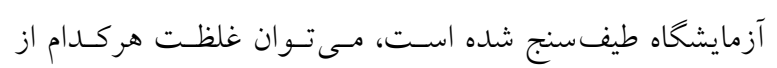

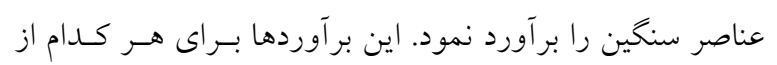

شده است، ضريب همبستكى بيرسون بين طيف هاى آزمايشـاهى

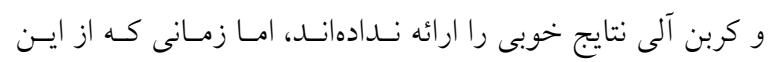

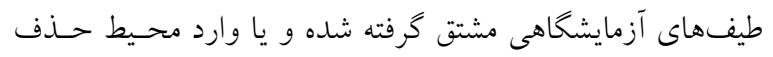

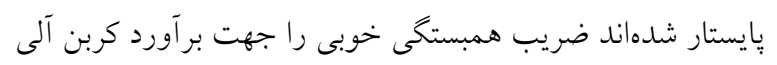

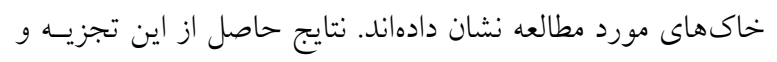

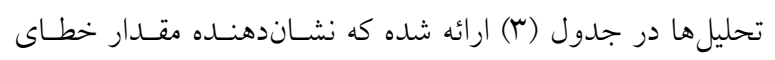

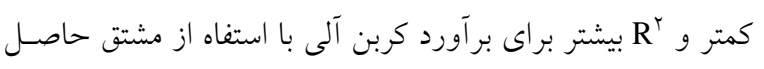

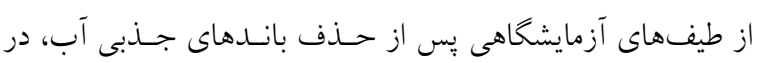

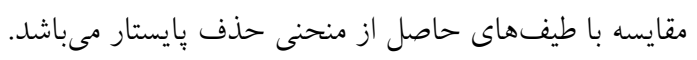
كربن آلى بيش بينى شده با استفاده از مدل حسداقل مربعـات جزعى PLSR همانطور كه قبلا اشاره شد، مشتق طيف هاى آزمايشكاهى در مقايسه

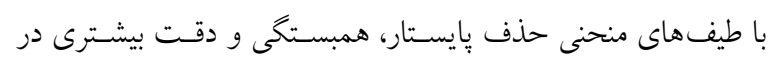

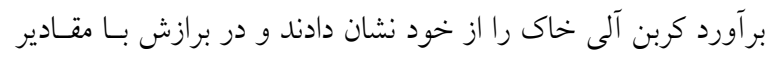

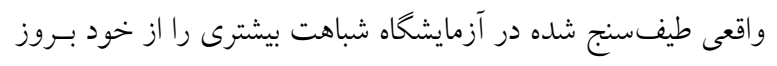


جدول ه. مقايسه مقادير اندازهيرى شده و بيشبينى شده نيكل (Ni)

\begin{tabular}{|c|c|c|c|c|c|c|c|c|c|}
\hline (ج) & (ب) & (الف) & درصد O.C & شماره نمونه & (ج) & (ب) & (الف) & درصد O.C & شماره نمونه \\
\hline $1 / \pi \mu$ & $T / Y I$ & $\circ / \mathrm{VA}$ &.$/ 94$ & 19 & $1 / \pi \mu$ & T/AY & $1 / 04$ & $1 / 14$ & 1 \\
\hline $1 / 49$ & $r / 09$ & ०/AV & $\circ / \Lambda 1$ & $r_{0}$ & I/VA & $r / D 1$ & $r / \circ \wedge$ & $1 / \pi 4$ & r \\
\hline 1/A。 & $r / \wedge \Delta$ & $r / 10$ & $1 / 91$ & rI & $1 / 94$ & $r / V \varphi^{c}$ & r/Or & $1 / \Lambda F$ & r \\
\hline T/YG & $r / 4 q$ & $1 / V 0$ & $\mathrm{r} / \mathrm{IV}$ & TY & I/VA & $r / 99$ & Y/V。 & $1 / V 9$ & k \\
\hline $1 / 11$ & $r / V Q$ & $T / D 1$ & $1 / 00$ & r & $1 / 99$ & $r / r V$ & $r / \circ r$ & $1 / V 0$ & 0 \\
\hline $1 / \wedge 1$ & T/VT & I/ETG & $1 / \Delta Y^{r}$ & YY & $1 / \wedge \Delta$ & $r / 9 T$ & 1/Or & $1 / \Delta \wedge$ & 4 \\
\hline I/AV & $r / \Delta D$ & 1/०r & $1 / 49$ & rQ & $1 / 41$ & $T / N Y^{C}$ & $1 / 1 \circ$ & $1 / \% \wedge$ & V \\
\hline $1 / \mu V$ & $r / \wedge \Delta$ & l/ky &.$/ 9 T$ & TG & $1 / \mu_{\Lambda}$ & T/NQ & $1 / N r$ & $.19 \mathrm{~V}$ & $\wedge$ \\
\hline T/YY & $r / 4 \varphi$ & ०/AV & $r / T$ & TV & $1 / \pi q$ & T/NV & $1 / 0 Y$ & 1 & 9 \\
\hline $1 / 94$ & $r / 99$ & $r / O \circ$ & $1 / \Lambda$ & rA & $1 / 00$ & $r / Q_{0}$ & $\circ / 9 \circ$ & $1 / 11$ & 10 \\
\hline $1 / V V$ & $r / 99$ & $0 / 99$ & l/Ar & rq & $1 / V V$ & T/AY & $1 / 01$ & $1 / 99$ & 11 \\
\hline $1 / 99$ & T/VT & $r / 01$ & $1 / 44$ & $\mu_{0}$ & $1 / V V$ & T/TQ & I/OY & $1 / 9 \pi$ & ir \\
\hline I/AT & $T / Y Y$ & $r / 04$ & $1 / 9 V$ & ו & $1 / \wedge \Delta$ & $r / \mu r$ & $1 / \Delta Y$ & $1 / N r$ & Ir \\
\hline $1 / K T$ & $r / \Lambda I$ & $1 / 90$ & $1 / 09$ & Tr & 1/A。 & $r / \circ r$ & $r / 4 \circ$ & $1 / \Lambda \Lambda$ & 14 \\
\hline $1 / 9 r$ & $r / 91$ & $r / \circ \wedge$ & $r / \circ Y$ & س & $1 / 4 \pi$ & T/VQ & $r / 09$ & $1 / 01$ & 10 \\
\hline $1 / 4 \wedge$ & Y/V。 & $1 / T V$ & $1 / 11$ & My & T/K & $T / N V$ & $r / r l$ & $r / T q$ & 19 \\
\hline $1 / 91$ & $r / \uparrow \wedge$ & $1 / 11$ & $1 / 1 T$ & ro & $1 / \mu_{\Lambda}$ & T/A & $1 / 14$ & $\circ / V 1$ & IV \\
\hline $1 / 91$ & $r / 09$ &.$/ 94$ & $1 / \Lambda \Lambda$ & re & $1 / \wedge \Delta$ & $T / N V$ & Y/०。 & 1/V9 & 11 \\
\hline
\end{tabular}

جدول 9. مقايسه مقادير اندازهيرى شده و بيشبينى شده نيكل (Pb)

\begin{tabular}{|c|c|c|c|c|c|c|c|c|c|}
\hline (ج) & (ب) & (الف) & درصد O.C & شماره نمونه & (ج) & (ب) & (الف) & درصد O.C & شماره نمونه \\
\hline $1 \wedge / \Gamma_{0}$ & $18 / 99$ & ID/T &.$/ 94$ & 19 & $1 / / T \Delta$ & $T / / \circ \Lambda$ & ro/VG & $1 / 14$ & 1 \\
\hline $1 N / \Delta Y^{Y}$ & $19 / V 1$ & $14 / 90$ & $\circ / 11$ & ro & YI/VG & $19 / 71$ & $1 / / \Delta 0$ & $1 / \pi 4$ & r \\
\hline$Y 1 / 91$ & $r \mid / \circ \Lambda$ & Tr/TG & $1 / 91$ & rI & ro/94 & $r \circ / \Delta 0$ & $18 / 94$ & $1 / \Lambda t$ & r \\
\hline$T Q / Y Y$ & $T Y / D Q$ & $r G / \circ D$ & T/IV & TT & YI/AI & $r \circ / T_{G}$ & $r Y / 01$ & 1/V9 & t \\
\hline $19 / 94$ & $r \circ / Q V$ & $19 / 10$ & $1 / 00$ & r & $r r / 41$ & rT/ & rN/9I & $1 / V 0$ & 0 \\
\hline TY/OI & $r \circ / r_{q}$ & $19 / 49$ & $1 / \Delta Y$ & TY & Tr/Tr & $r 1 / 00$ & $r V / \circ T$ & $1 / 01$ & 9 \\
\hline$r Y / Y \circ$ & 19/0 & $r V / Q_{0}^{\circ}$ & $1 / 49$ & ro & $11 / 94$ & $r 0 / 01$ & $r 9 / T^{\circ}$ & $1 / \mu \Lambda$ & V \\
\hline $11 / 94$ & $r M / 10$ & $19 / 90$ &.$/ 9 r$ & rG & $11 / 99$ & $r 0 / 91$ & $T Y / 01$ & $0 / 9 \mathrm{~V}$ & $\wedge$ \\
\hline سM/T & YY/MA & IV/OT & $T / T$ & TV & IN/VA & ro/9q & rN/QT & 1 & 9 \\
\hline$r Y / 9 V$ & $r \circ / \circ V$ & TY/T & $1 / 1$ & YA & $19 / 99$ & $19 / T 4$ & $10 / 09$ & $1 / 11$ & 10 \\
\hline$T \mid / V I$ & TI/AV & $N / 0 / r$ & l/AT & rq & $r 1 / 99$ & $T I / \circ V$ & $9 / 090$ & $1 / 99$ & 11 \\
\hline$r \circ / \Lambda \Lambda$ & $r \circ / \mu q$ & KY/YG & $1 / 44$ & r。 & TI/V。 & Tr/TV & r9/99 & $1 / 94$ & IT \\
\hline$r Y / \circ V$ & Tr/Tr & $1 \mathrm{H} / 9 \mathrm{~V}$ & $1 / 9 \mathrm{~V}$ & m & $Y Y / T V$ & TY/GY & $r \circ / D 1$ & $1 / N$ & Ir \\
\hline$M / T_{0}$ & $r 0 / 91$ & $r Q / A V$ & $1 / 09$ & rt & TI/AG & TY/OG & TV/OH & $1 / M$ & 14 \\
\hline TY/AY & TI/TH & $r V / \Lambda q$ & $r / O Y$ & r & $19 / 0 r$ & $r 0 / 91$ & $I T / V Y$ & $1 / 01$ & 10 \\
\hline $19 / 4 \Lambda$ & $r_{0} / \mu_{0}$ & IN/VG & $1 / 11$ & ry & $Y Y / D I$ & $r \circ / V T$ & $\mu y / \circ \Lambda$ & $T / Y q$ & 19 \\
\hline$r \circ / 4 q$ & $19 / 14$ & $11 / 4 q$ & $1 / 1 Y$ & ro & $11 / 99$ & $r \mid / 01$ & $10 / 49$ & $\circ / V I$ & IV \\
\hline ג & TY/TY & Tr/QT & $1 / \Lambda \Lambda$ & ra & $T Y / T q$ & ro/91 & זץ/אז & $1 / V 9$ & 11 \\
\hline
\end{tabular}


مىتوانند جهت تعيين غلظت فلـزات سـنخين، از طريـق ايجـاد همبستخى معنى دار بين اين اجزا و غلظتهاى فلزات سنخين در محدودههاى طيفى مادون قرمز نزديـك و كوتـاه، نتـايج بسـيار خوبى را به ارمغان بياورند. البته بايد خاطر نشـان نمـود كـه در

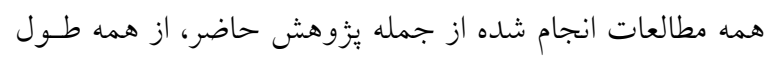
موجهاى انعكاسى كفته شده نبايد در برآوردها استفاده كرد. تجرا كه محدودههاى طيفى جذب آب و همجتنـين محسدودههـاى بـا امواج ناكار آمد نتايج صحيحى را در تشخيص و تعيسين فلـزات سنخين بهدست نمى دهند. يافتههاى بزوهش حاضر با يافتههـاى

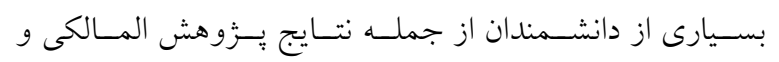

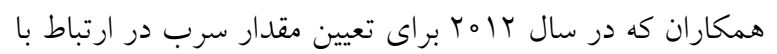

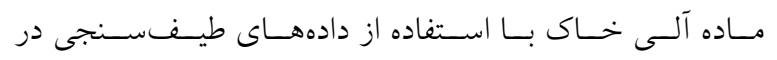
محدودههاى مادون قرمز نزديك و مادون قرمز كوتاه انجام شد،

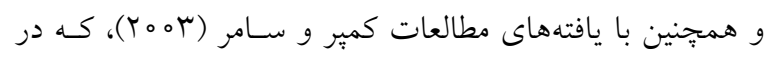
ارتباط با برآورد غلظت و آلودگى فلزات سنخين انجام يذيرفت،

$$
\text { همخوانى بسيارى دارد. }
$$

عناصر نيكـل (Ni) و سـرب (Pb) در جــاول (ه) و (4) آورده شده و با مقادير واقعى حاصل از طيفسنج با استفاده از دستگاه جذب اتمى مقايسه شدهاند. همـانطـور كـه نتـايج موجـود در جدول (Y) نيز نشان مى دهند، مشتق طيف مهاى بـهدسـت آمـده، دقت و كارآيى بيشترى را در تشـخيص عناصسر سـنخين مـورد آزمايش داشتهاند.

\section{نتيجه كيرى}

نتايج حاصل از اين يزوهش نشان داد كـه انعكـاس هــاى طيفى

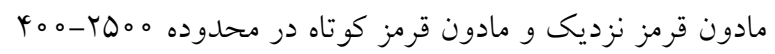

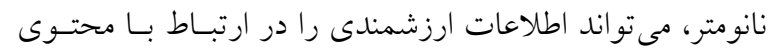

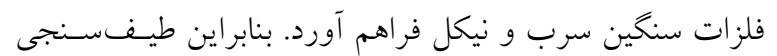
انعكاسى، توانايى بالايى در ارائه يك روش سريع و كـم هزينـه

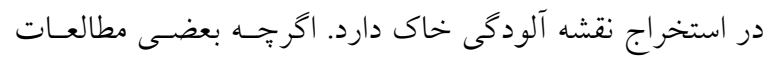
نشان دادهاند كه طيف هاى انعكاسى بين فلزات سنخين و اجزاى

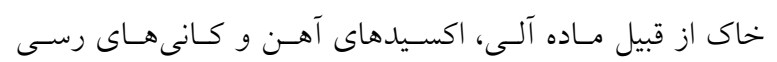

$$
\begin{aligned}
& \text { ا. انصارى، م. هیrا. بررسى وضعيت آلودگى رسوبات رودخانه كارون با عناصر سنخين آلاينده حدفاصل بند قير تـا جنـوب اهـواز. } \\
& \text { پايان نامه كارشناسى ارشد، دانشخاه آزاد اسلامى، واحد علوم وتحقيقات منطقه } 9 \text { اهواز. }
\end{aligned}
$$

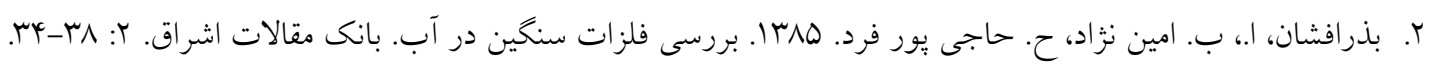

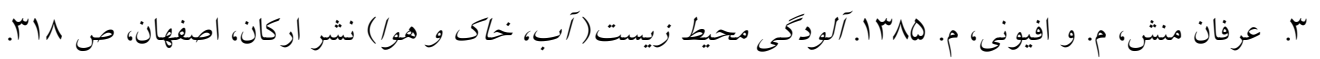

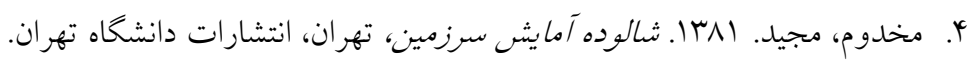

5. Adriano, D. C. 2001. Trace elements in terrestrial environments, biogeochemistry, bioavailability and risks of metals. PP: 78-79. second edition. Springer, New York.

6. Al Malikia, A., G. Owensa. and D. Bruce. 2012. Capabilities of remote sensing hyper spectral images for the detection of lead contamination: A review. ISPRS Ann. Ph, RS \& Spat. Info. Sci. I-7: 55-60.

7. Bacon, J. R. and C. M. Davidson. 2008. Is there a future for sequential chemical extraction? Analyst. 133: 25-46.

8. Ben-Dor, E., D. Chabrillat, H. Taylor and S. Whiting. 2009. Using imaging spectroscopy to study soil properties. Remote Sens. Environ. 113: S38-S55.

9. Carter, M. R. and E. G. Gregorich. 2007. Soil sampling and methods of analysis. pp: 102. Taylor \& Francis Group.

10. Choe, M., S. D. W. Ruitenbeek. and K-W. Kim. 2008. Mapping of heavy metal pollution in stream sediments using combined geochemistry, field spectroscopy, and hyperspectral remote sensing: A case study of the Rodalquilar mining area, SE Spain. Remote Sens. Environ. 112: 3222-3233.

11. Farifteh, J., F. Van der Meer, C. Atzberger and E. J. M. Carranza. 2007. Quantitative analysis of salt-affected soil reflectance spectra: A comparison of two adaptive methods (PLSR and ANN). Remote Sens. Environ. 110: 59-78.

12. Gagnon, C., M. Arnac and J. R. Brindle. 1992. Sorption interactions between trace metals (Cd and Ni) and phenolic substances on suspended clay minerals. Water Res. 26: 1067-1072.

13. Gleeson, D. R., S. Pappalardo, M. Grasby, B. B. Anderson, S. A. R. Castaño, T. D. Chien, M. Lukas and L. H. Kiri. 
2006. Spectral mapping tools from the earth sciences applied to spectral microscopy data. Int. Soci. Analyt. Cyt. 69: 872-879.

14. Kemper, T. and S. Sommer. 2003. Mapping and monitoring of residual heavy metal contamination and acidification risk after the Aznalcóllar mining accident (Andalusia, Spain) using field and airborne hyperspectral data. In: the 3rd EARSeL Workshop on Imaging Spectroscopy, Herrsching.

15. Kesraoui-Ouki, S., C. Cheeseman and R. Perry. 1994. Natural zeolite utilisation in pollution control: A review of applications to metals’ effluents. J. Chem. Technol. Biotechnol. 59: 121-126.

16. Lado, L. R., T. Hengl and H. I. Reuter. 2008. metals in European soils: a geostatistical analysis of the FOREGS Geochemical database. Geoderma 148: 189-199.

17. Lee, L. X. and W. Shi. 2006. Metal contamination in urban, suburban, and country park soils of Hong Kong: A study based on GIS and multivariate statistics. Sci. Total Environ. 356(1-3): 45-61.

18. Lênio Soares, G., F. Antônio Roberto and C. Eduardo Guimarães. 2008. Relationships between the mineralogical and chemical composition of tropical soils and topography from hyperspectral remote sensing data. ISPRS J. Photogramm Remote Sens. 63: 259 - 271.

19. Minasny, T. and B. McBratney. 2009. Regional transferability of mid-infrared diffuse reflectance spectroscopic prediction for soil chemical properties. Geoderma 153: 155-162.

20. Orhan, Y. and H. Büyükgüngör. 1993. The Removal of Heavy Metals by Using Agricultural Wastes. Water Sci. Technol. 28(2): 247-255.

21. Pandit, F. and L. Li. 2010. Estimation of heavy-metal contamination in soil using reflectance spectroscopy and partial least-squares regression. Int. J. Remote Sens. 31(15): 4111-4123.

22. Philippe, L., F. Baret, J. B. Feret, J. Maderia Netto and J. M. Robbez-Masson. 2008. Estimation of soil clay calcium carbonate using laboratory, field, airborne hyperspectral measurements. Remote Sens. Environ. 112: 825-835.

23. Rossel, R. A., D. J. J. Walvoort, B. McBratney, L. J. Janik and J. Skjemstad. 2006. mid infrared or combined diffuse reflectance spectroscopy for simultaneous assessment of various soil properties. Geoderma 131: 59-75.

24. Schwartz, E. and E. Ben-Dor. 2012. Reflectance Spectroscopy as a Rapid Tool for Monitoring Contaminated Soil. PhD thesis. Porter School of environmental studies, Tel Aviv University.

25. Song, J. J., Y. X. Yuan and Z. Yang. 2010. Diffuse reflectance spectroscopy study of heavy metals in agricultural soils of the Changjiang River Delta, China. In: 19th World Congress of Soil Science, Soil Solutions for a Changing World, Brisbane, Australia.

26. Sprynskyy, M., B. Buszewski, A. P. Terzyk and J. Namiesnik. 2006. Study of the selection mechanism of heavy metal $\left(\mathrm{Pb}^{2+}, \mathrm{Cu}^{2+}, \mathrm{Ni}^{2+}\right.$, and $\left.\mathrm{Cd}^{2+}\right)$ adsorption on clinoptilolite. J. Colloid Interface Sci. 304: 21-28.

27. Unal, H. I. and B. Erdogan. 1998. The use of sepiolite for decolorization of sugar juice. Appl. Clay Sci. 12: 419429.

28. Vohland, B. F. 2009. A spectroscopic approach to assess trace-heavy metal contents in contaminated floodplain soils via spectrally active soil components. J. Plant Nutr. Soil Sci. 172(2): 201-209.

29. Winkelmann, K. H. 2005. On the Applicability of Imaging Spectrometry for the Detection and Investigation of Contaminated Sites with Particular Consideration Given to the Detection of Fuel Hydrocarbon Contaminants in Soil. PhD thesis. Faculty of Environmental Sciences and Process Engineering, Brandenburg University of Technology.

30. Wold, S., M. Sjostrom. L. Eriksson. 2001. PLS-regression: a basic tool of chemometrics. Chemometr. Intell. Lab. Syst. 58: 109-130.

31. Wong, S. C., X. D. Li, G. Zhang, S. H. Qi and Y. S. Min. 2002. Heavy metals in agricultural soils of the Pearl River Delta, South China. Environ. Pollut. 119: 33-44.

32. Wu, Y. C., Q. Tian and X. Wu. 2005. Feasibility of reflectance spectroscopy for the assessment of soil mercury contamination. Environ. Sci. Technol. 39(3): 873-878.

33. Yalcin, M. G., R. Battaloglu, and S. Ilhan. 2007. Heavy metal sources in Sultan Marsh and its neighborhood, Kayseri, Turkey. Environ. Geol. 53: 399-415.

34. Zhang, Z., J. Wen and D. Zhao. 2010. Band selection method for retrieving soil lead content with hyperspectral remote sensing data. Soci. Photo-Optical Inst. Engin. (SPIE). 7831. 


\title{
Assessment of Visible and Near-Infrared Spectroscopy in Estimation of Lead and Nickel Heavy Metals content in Soil (Case study: Rey Lands)
}

\author{
R. Samiei Fard ${ }^{* 1}$ and H. Matinfar ${ }^{2}$
}

(Received: Jan. 12-2016 ; Accepted: April 03-2017)

\begin{abstract}
Reflectance spectroscopy is a fast and safe method to predict soil physicochemical and biological properties in low cost ways. Traditional methods to determine soil properties require spending a lot of time and money so that farmers are generally reluctant to use the results of laboratory measurements in soil and water management. Reflectance spectroscopy in the spectral range of $400-2500 \mathrm{~nm}$ (VNIR) is an alternative method for estimating the soil properties. The aim of this study was to evaluate the results of laboratory spectrometer to estimate the concentration of Lead (Pb) and Nickel (Ni) in soils irrigated with water from treatment of urban sewage sludge of Rey city and finally to compare these results with the results of measurements of atomic absorption spectrometry. In this study, the Partial Linear Square Regression (PLSR) model was used to estimate the concentration of heavy metals and Residual Mean Square Error (RMSE) was used to evaluate the performance of this model. In this research, after spectral corrections related to elimination of the water absorption bands as well as elimination of the inefficient spectrum from heavy metals estimations, the methods of estimating these elements were studied through mathematical derivation of spectral values and also the acquisition of the continuum removal spectra. The results show that the estimated values from first derivate spectra are more consistent with the results of atomic absorption spectrometers.
\end{abstract}

Keywords: Reflectance Spectroscopy, Atomic Adsorption Spectroscopy, Heavy Metals, PLSR, Visible and Near Infrared.

1. Dept. of Soil Sci. Eng., Facalty of Agric., Tehran Univ., Tehran. Iran.

2. Dept. of Soil Sci., Faculty of Agric., Lorestan Univ., Lorestan. Iran.

*: Corresponding Author, Email: ramin.samiei@ut.ac.ir 